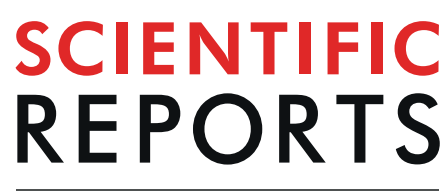

natureresearch

\title{
Preparation of a novel nitrogen- containing graphitic mesoporous carbon for the removal of acid red 88
}

\author{
Qiying Zhou ${ }^{1,2,3}$, Wenhua Chen ${ }^{1,2,3}$, Xia Jiang ${ }^{1,2^{*}}$, Hongying Liu ${ }^{1,2}$, Shenggui Ma ${ }^{1,2} \&$ \\ Bangda Wang ${ }^{1,2}$
}

\begin{abstract}
A novel nitrogen-containing graphitic mesoporous carbon was prepared through MnO-templated method using polyacrylonitrile (PAN) as both carbon and nitrogen sources, and $\mathrm{MnCO}_{3}$ as both template and catalyst precursors. The effects of preparation conditions on the physicochemical properties of obtained samples were systematically investigated. The results showed that as the decrease of the weight ratios of PAN and $\mathrm{MnO}(2: 1-1: 4)$, the increase of carbonization temperature $\left(700-900^{\circ} \mathrm{C}\right)$ and pre-oxidation temperature $\left(180-200^{\circ} \mathrm{C}\right)$, the samples had higher specific surface area, mesopores volume and ratios, up to $507 \mathrm{~m}^{2} / \mathrm{g}, 0.824 \mathrm{~cm}^{3} / \mathrm{g}$ and $96.83 \%$, respectively. Moreover, the prepared samples presented relatively high graphitic degree and nitrogen contents $(-2.21 \%)$. The adsorption capacity for acid red 88 (AR88) was as high as $309 \mathrm{mg} / \mathrm{g}$, which were dramatically affected by the mesoporous properties and $\mathrm{C}$ - and $\mathrm{N}$-containing groups on the surface of prepared carbon. The rich graphic carbon and pyridine- $\mathrm{N}$ in mesoporous carbon generated $\pi-\pi$ dispersion and electrostatic interaction with AR88, respectively, which jointly were responsible for the adsorption process. The results of the isotherm and kinetic studies indicated that the AR88 adsorption on mesoporous carbon could be well depicted using Langmuir model and pseudo- $2^{\text {nd }}$-order model.
\end{abstract}

Recently, the demand for dyes is increasing, with the fast development of industries, including textile, printing, paper making, cosmetic, etc. The dye wastewater has gradually become one of the vital pollutants, which seriously affects both human beings' health and environment. Thus, it is significantly important for the removal of dye pollutants from wastewater before discharging into environment. However, it is a great challenge to treat dye wastewater, because of its high resistance to photo-degradation, oxidation and bio-degradation ${ }^{1}$. It was reported that the adsorption by mesoporous carbon (i.e. pores size from 2 to $50 \mathrm{~nm}$ ) is a desirable method for the removal of dye pollutants with large molecules diameters, with many advantages such as easy operation, high efficiency, and the recycle of dye $\mathrm{e}^{2-4}$. In comparison with the microporous adsorbent, the mesoporous carbon possessed higher adsorption capacity for the large dye molecules ${ }^{5-7}$. The adsorption rate could also be significantly enhanced by introducing the mesoporous structure into the carbon materials ${ }^{8}$.

Normally, various hard templates including zeolites, mesoporous silica are used to prepare the mesoporous carbon by removing these ordered structural frameworks. This strategy has been given extensive attention in the literature due to the high stability of templates and precise control for porous structure ${ }^{9}$. However, when removing these hard templates, some strong corrosive agents like hydrofluoric acid and sodium hydroxide are used, which will always cause unavoidable corrosion, and the templates are obliged to be wasted ${ }^{10}$. In this way, the high preparation cost of the template method seriously hinders its application in practical industry. Therefore, developing a clean and efficient template is significant for the preparation of mesoporous carbon. $\mathrm{MnO}$, as an alternative template, shows high thermal stability and the tunable pore size can be easily given by decomposing its precursors. Then the pores are attained by isolating the generated nano- $\mathrm{MnO}$ using the diluted low-corrosive acid solution, like $\mathrm{HCl}$ and $\mathrm{H}_{2} \mathrm{SO}_{4}$. More importantly, the $\mathrm{MnO}$ templates can be cyclically utilized from the pickling solution. Thus, this strategy simultaneously enhances the operation safety and lowers the preparation cost.

On the other hand, the chemically inert and poorly hydrophilic surface of mesoporous carbon severely limited its application as the efficient absorbent for dye pollutants. Thus, it is necessary to develop some useful strategies to realize the surface modification of mesoporous carbon. Recently, massive methods ${ }^{11}$ have been applied to

${ }^{1}$ College of Architecture and Environment, Sichuan University, Chengdu, 610065, China. ${ }^{2}$ National Engineering Research Centre for Flue Gas Desulfurization, Chengdu, 610065, China. ${ }^{3}$ These authors contributed equally: Qiying Zhou and Wenhua Chen. *email: xjiang@scu.edu.cn 


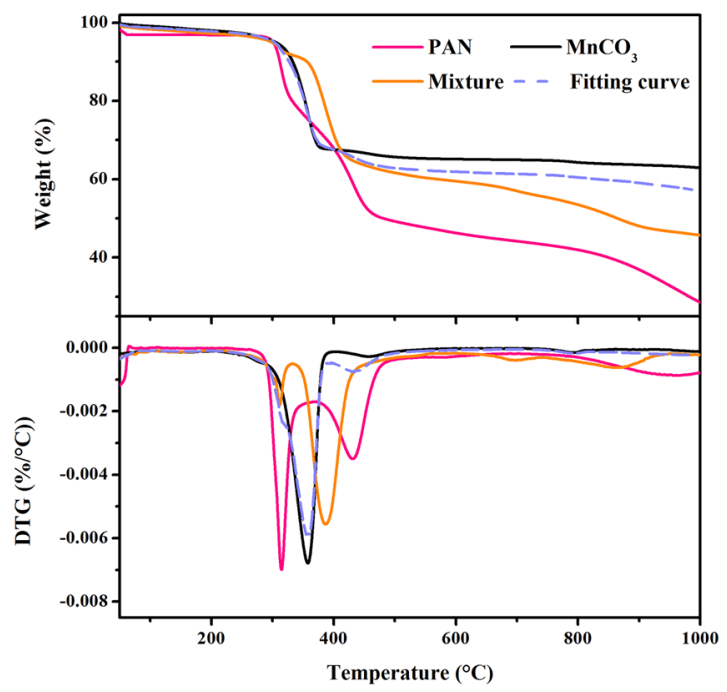

Figure 1. TG and DTG curves of $\mathrm{PAN}, \mathrm{MnCO}_{3}$, their mixture with weight ratio of 1:3 and the related fitting curve.

improve the surface properties of the mesoporous carbon, among which, nitrogen doping is considered as an effective one and has attracted increasing attention. Previous studies showed that both the adsorption capacity and the rate of the anionic dye by carbon materials could be enhanced significantly when the nitrogen-containing groups were doped on the surface of carbon ${ }^{12,13}$. There are two common approaches to introduce nitrogen into carbon, i.e. $\mathrm{NH}_{3}$ gas post-modification and in situ doping. However, the post-modification could increase the complexity and the cost of the preparation process, together with high corrosivity during the operation process, thus severely inhibiting its wide application. In contrast with the post-modification, the in situ procedure can ensure the homogeneous doping of nitrogen throughout the entire mesoporous carbon material ${ }^{14}$. It could be a suitable method for the preparation of $\mathrm{N}$-doped carbon material by using the carbon materials with a high content of nitrogen ${ }^{15}$. Polyacrylonitrile (PAN) is a kind of polymer material with a high content of $\mathrm{C} \equiv \mathrm{N}$ functional group, which presents great potential as both carbon and nitrogen precursors for the preparation of N-doped mesoporous carbon ${ }^{16}$. Liu et al. ${ }^{17}$ fabricated $\mathrm{N}$-doped ordered porous carbon by the nano-casting process using PAN as carbon and nitrogen precursors, with nitrogen content up to $6.88 \%$. In addition, it was reported that manganese compounds presented an excellent catalyst for the graphitization of carbon at around $1000^{\circ} \mathrm{C}$, i.e. manganese oxides ${ }^{18,19}$. Such graphitic structure could promote the adsorption of dye molecules with aromatic ring via $\pi-\pi$ dispersion interaction ${ }^{20,21}$. However, few studies have been conducted on using manganese salts as both template and catalyst precursors for the preparation of graphitic mesoporous carbon.

Thus, in this study, a novel nitrogen-containing graphitic mesoporous carbon was prepared by MnO-template method using PAN as both carbon and nitrogen sources, together with commercial $\mathrm{MnCO}_{3}$ as both template and catalyst precursors. The effects of $\mathrm{MnCO}_{3}$ on the carbonization and graphitization of PAN molecules was investigated. The influences of preparation conditions on the physicochemical properties and acid red 88 (AR88) adsorption process of prepared carbon were discussed, including weight ratios of PAN and $\mathrm{MnO}$, carbonization temperature and pre-oxidation temperature. Finally, the isotherm and kinetics of the adsorption process were provided.

\section{Results}

Characterization of mesoporous carbon. TG analysis. Figure 1 presents the TG and DTG curves of $\mathrm{PAN}, \mathrm{MnCO}_{3}$ and their mixture (weight ratio = 1:3) in $\mathrm{N}_{2}$ atmosphere. The pyrolysis of PAN could be divided into four stages. The first stage was from room temperature to $175^{\circ} \mathrm{C}$ with about $4 \%$ of weight loss, which could be ascribed to the evaporation of $\mathrm{H}_{2} \mathrm{O}$ and acrylonitrile monomer remained on the surface of PAN. The second weight-loss stage happened from $175^{\circ} \mathrm{C}$ to $350^{\circ} \mathrm{C}$, with about $31 \%$ of weight loss and the DTG peak located at $315^{\circ} \mathrm{C}$. In this stage, the $-\mathrm{C} \equiv \mathrm{N}$ was transformed to $-\mathrm{C}=\mathrm{N}$ with the escape of $\mathrm{HCN}$ and the generation of $\mathrm{C}=\mathrm{C}^{22}$. The third weight-loss stage from 350 to $500^{\circ} \mathrm{C}$ was corresponded to the hemolytic cleavage, cyclization and aromatization of PAN, with the release of $\mathrm{HCN}, \mathrm{NH}_{3}$ and some $\mathrm{N}$-containing light alkenes, resulting in the loss of $\mathrm{H}$ and $\mathrm{N}$ atoms and residue of C-rich pyrolysis solid ${ }^{23}$. After $500^{\circ} \mathrm{C}$, the fourth stage occurred, with about $30 \%$ of weight loss, especially over $800^{\circ} \mathrm{C}$, which could be ascribed to the elimination of non-carbon atoms and realignment of the carbon structure. However, definite graphitization is not possible for the carbonized PAN without pre-oxidation and catalyst at this temperature range. As clearly seen in Fig. 1, only one weight-loss stage could be observed during the pyrolysis of $\mathrm{MnCO}_{3}$ within $1000^{\circ} \mathrm{C}$, from 300 to $390^{\circ} \mathrm{C}$ with about $37 \%$ of weight loss, and the DTG peak was located at $358^{\circ} \mathrm{C}$. Based on the ratio of weight loss, it could be assumed that the decomposition products of $\mathrm{MnCO}_{3}$ were $\mathrm{MnO}$ and $\mathrm{CO}_{2}$. In addition, no further weight loss occurred after $390^{\circ} \mathrm{C}$, which indicates that the produced $\mathrm{MnO}$ kept stable within $1000^{\circ} \mathrm{C}$. 

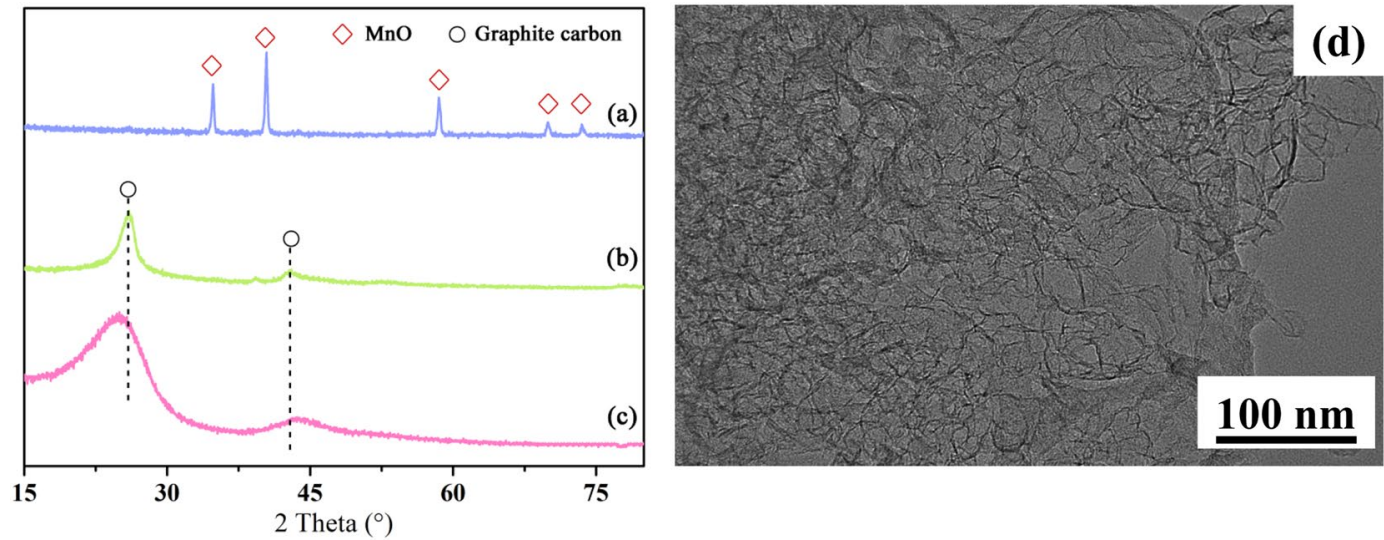

Figure 2. XRD patterns of carbonized samples (the mixture with the weight ratio of PAN and MnO at $1: 3$ before (a) and after acid washing (b), carbonized PAN (c)); high-resolution TEM image of carbonized samples after acid washing.

To analyze the effect of $\mathrm{MnCO}_{3}$ on the decomposition of PAN, the fitting TG and DTG curves were calculated from the curves of $\mathrm{MnCO}_{3}$ and PAN with the weight ratio of $1: 3$. Before $320^{\circ} \mathrm{C}$, the TG curves of the fitting and the mixture were coincided, indicating that no interactions occurred between $\mathrm{PAN}$ and $\mathrm{MnCO}_{3}$ within this temperature range. When the temperature got higher, the two curves started to diverge. From 320 and $400{ }^{\circ} \mathrm{C}$, the weight loss of the mixture was delayed, compared with the fitting curve, which might be ascribed to the inhibition of PAN pyrolysis or $\mathrm{MnCO}_{3}$ decomposition. However, from 480 to $1000^{\circ} \mathrm{C}$, the mixture curve presented much more weight loss (about 11\%) than the fitting one, indicating that the existence of $\mathrm{MnO}$ could accelerate the decomposition of PAN at a higher temperature.

The TG and DTG curves of the mixture after pre-oxidation $\left(200^{\circ} \mathrm{C}\right.$ for $\left.1 \mathrm{~h}\right)$ are illustrated in Fig. S1. It can be seen that the pre-oxidized mixture presented similar DTG peaks to one without pre-oxidation, while their weight loss curves were slightly different. Even though the reaction degree was very low in this period, they are vital for the cyclization of PAN molecules in the following carbonization and could help reduce the weight $\operatorname{loss}^{24}$. Zhao et al. ${ }^{25}$ reported that during the pre-oxidization process at around $200^{\circ} \mathrm{C}$, the PAN was converted to an infusible stable ladder polymer by the movement of $\mathrm{C} \equiv \mathrm{N}$ in acrylonitrile units into $\mathrm{C}=\mathrm{N}$ bonds and the generation of $\mathrm{C}=\mathrm{O}$ groups in comonomer units.

TEM and XRD analysis. The XRD patterns of the carbonized sample at $900^{\circ} \mathrm{C}$ before and after acid washing are shown in Fig. 2. It can be seen that the peaks at $2 \theta=34.9^{\circ}, 40.55^{\circ}, 58.72^{\circ}, 70.18^{\circ}$ and $73.79^{\circ}$ could be observed for the carbonized sample before acid washing, which was ascribed to $\mathrm{MnO}$. This indicates that $\mathrm{MnO}$ was the only crystalline substance existing in the carbonized sample. Combined with the TG analysis (Fig. 1), it could be confirmed that $\mathrm{MnO}$ kept stable during the carbonization process.

As shown in Fig. 2, after acid washing of the carbonized sample, the diffraction peaks of Mn compounds disappeared, while only the peaks ascribed to graphite carbon could be detected. This reveals that the MnO was completely removed and the carbonized sample presented a clearly graphitized structure. The XRD pattern of the carbonized pristine PAN with the same conditions of mixture sample was also given, whose peaks belonging to graphitized carbon were evidently broader than those of the sample with the addition of $\mathrm{MnCO}_{3}$. This indicates that after the addition of $\mathrm{MnCO}_{3}$, the crystallization degree of the mixture sample was clearly higher. Furthermore, the (002) diffraction plane of the samples with and without $\mathrm{MnCO}_{3}$ addition appeared at $2 \theta=26.08$ and $24.96^{\circ}$, respectively, with the corresponding $\mathrm{d}_{002}=3.41 \AA$ and $3.57 \AA$. It was reported that the perfect hexagonal graphite has a $\mathrm{d}_{002}$ value of $3.35 \AA$, suggesting that the mixture sample has a better-graphitized structure. As shown in TG analysis (Fig. 1), the existence of $\mathrm{MnO}$ could promote the decomposition of PAN during 480 to $1000^{\circ} \mathrm{C}$, which could result in the difference on carbon structure between the samples with and without $\mathrm{MnCO}_{3}$. This confirmed the catalysis effect of $\mathrm{MnO}$ on the graphitization of PAN.

Oya and Marsh ${ }^{26}$ proposed four types of effects of catalytic graphitization, including G-effect, Ts-effect, A-effect and Tn-effect. As shown in Fig. 2, the peaks belonging to graphite carbon for the mixture sample were symmetrical and well-proportioned, suggesting that the effects of MnO catalytic graphitization on PAN seemed to be due to the A-effect. It was reported that the A-effect was caused by the catalyst with ultra-fine diameters, like the metallic vapour, which could result in a more homogenous effect of catalysts for carbon precursors. However, in this study, no Mn species could be gasified within this temperature range (below $900^{\circ} \mathrm{C}$ ), suggesting that there might be some other effects existed. The porous structure created in carbons was further studied using the transmission electron microscope (TEM) observation and the related images were shown in Fig. $2 \mathrm{~d}$. It can be clearly seen from Fig. 2d, the prepared carbon after acid washing shows well-developed porous structure with abundant mesopores.

Textural properties. The $\mathrm{N}_{2}$ adsorption-desorption isotherms of the prepared carbon are given in Fig. S2. All curves presented a low $\mathrm{N}_{2}$ adsorption capacity at a lower relative pressure (below 0.01) and a remarkable uptake 


\begin{tabular}{|l|l|l|l|l|l|l|}
\hline Preparation condition & Value & $\mathbf{S}_{\text {BET }}\left(\mathbf{m}^{2} / \mathbf{g}\right)$ & $\mathbf{V}_{\text {tot }}\left(\mathbf{m}^{3} / \mathbf{g}\right)$ & $\mathbf{V}_{\text {mic }}\left(\mathbf{c m}^{3} / \mathbf{g}\right)$ & $\mathbf{V}_{\text {meso }}\left(\mathbf{c m}^{3} / \mathbf{g}\right)$ & $\mathbf{V}_{\text {meso }} / \mathbf{V}_{\text {tot }}(\%)$ \\
\hline \multirow{5}{*}{ Weight ratio (PAN:MnO) } & $2: 1$ & 164 & 0.399 & 0.018 & 0.381 & 95.49 \\
\cline { 2 - 7 } & $1: 1$ & 282 & 0.686 & 0.026 & 0.660 & 96.21 \\
\cline { 2 - 7 } & $1: 2$ & 411 & 0.705 & 0.021 & 0.684 & 97.02 \\
\cline { 2 - 7 } & $1: 3$ & 489 & 0.881 & 0.027 & 0.854 & 96.94 \\
\cline { 2 - 7 } & $1: 4$ & 507 & 0.851 & 0.027 & 0.824 & 96.83 \\
\cline { 2 - 7 } & $1: 5$ & 455 & 0.745 & 0.023 & 0.722 & 96.91 \\
\hline \multirow{5}{*}{ Carbonization temperature $\left({ }^{\circ} \mathrm{C}\right)$} & 700 & 45 & 0.040 & 0.016 & 0.024 & 60.00 \\
\cline { 2 - 7 } & 800 & 371 & 0.464 & 0.024 & 0.440 & 94.83 \\
\cline { 2 - 7 } & 900 & 489 & 0.881 & 0.027 & 0.854 & 96.94 \\
\cline { 2 - 7 } & 950 & 472 & 0.859 & 0.026 & 0.833 & 96.97 \\
\hline \multirow{5}{*}{ Pre-oxidation temperature $\left({ }^{\circ} \mathrm{C}\right)$} & - & 362 & 0.604 & 0.028 & 0.576 & 95.36 \\
\cline { 2 - 7 } & 180 & 439 & 0.749 & 0.022 & 0.727 & 97.06 \\
\cline { 2 - 7 } & 200 & 489 & 0.881 & 0.027 & 0.854 & 96.94 \\
\cline { 2 - 7 } & 240 & 337 & 0.449 & 0.026 & 0.423 & 94.21 \\
\hline After adsorption & - & 127 & 0.369 & 0.000 & 0.369 & 100 \\
\hline
\end{tabular}

Table 1. Textural properties of prepared samples.

when the relative pressure was higher than 0.4 . An evident hysteresis loop could be observed, indicating that all of the prepared carbon could be classified as mesoporous materials.

The porous properties of prepared carbons calculated from the isotherms were summarized in Table 1. It can be seen that their $\mathrm{S}_{\mathrm{BET}}$ increased from 164 to $507 \mathrm{~m}^{2} / \mathrm{g}$ with the decrease of the weight ratios of PAN and template from 2:1 to 1:4, while subsequently declined to $455 \mathrm{~m}^{2} / \mathrm{g}$ when the ratio was $1: 5$. Their $\mathrm{V}_{\text {tot }}$ and $\mathrm{V}_{\text {meso }}$ also increased from 0.399 and $0.381 \mathrm{~cm}^{3} / \mathrm{g}$ to 0.881 and $0.854 \mathrm{~cm}^{3} / \mathrm{g}$, respectively, with the weight ratios ranging from $2: 1$ to $1: 3$, while dropped to 0.745 and $0.722 \mathrm{~cm}^{3} / \mathrm{g}$ when the ratio was $1: 5$. This indicates that the template was filled with the inner parts of carbon when the ratio was about 1:3. The $\mathrm{V}_{\text {meso }} / \mathrm{V}_{\text {tot }}$ ratios of all samples were high, above $95 \%$, while their $\mathrm{V}_{\text {mic }}$ was evidently low (i.e. $0.018-0.027 \mathrm{~cm}^{3} / \mathrm{g}$ ) and roughly invariant with the change of template contents. This suggests that the micropores are created caused by the decomposition process of the carbon precursor (i.e. PAN), while the mesopores were from the templates.

Their mesopores size distributions are plotted in Fig. 3(a). The prepared carbon exhibited a relatively narrow pore size distribution with a peak at around $12.5 \mathrm{~nm}$. Furthermore, with decreasing the weight ratio of PAN and $\mathrm{MnO}$ from 2:1 to 1:3, the height of the peaks gradually increased first and then dropped a little when the weight ratios were lower than 1:4. This also indicates that the mesopores were generated from the removal of the template and the weight ratio of PAN and template was the key factor affecting the mesopore contents.

The textural properties of mesoporous carbon prepared at different temperature are also tabulated in Table 1. The $\mathrm{S}_{\mathrm{BET}}, \mathrm{V}_{\text {tot }}$ and $\mathrm{V}_{\text {meso }}$ of the sample carbonized at $700^{\circ} \mathrm{C}$ were only $45 \mathrm{~m}^{2} / \mathrm{g}, 0.040 \mathrm{~cm}^{3} / \mathrm{g}$ and $0.024 \mathrm{~cm}^{3} / \mathrm{g}$, respectively, suggesting that little pores could be produced when carbonization temperature was $700^{\circ} \mathrm{C}$ (Fig. S2(b)). The porous structure of the samples with carbonization temperature over $800^{\circ} \mathrm{C}$ turned to be evidently richer, with $S_{\mathrm{BET}}, \mathrm{V}_{\text {tot }}$ and $\mathrm{V}_{\text {meso }}$ at $489 \mathrm{~m}^{2} / \mathrm{g}, 0.881 \mathrm{~cm}^{3} / \mathrm{g}$ and $0.854 \mathrm{~cm}^{3} / \mathrm{g}$, respectively, for the sample at $900^{\circ} \mathrm{C}$. With a further increase of carbonization temperature at $950^{\circ} \mathrm{C}$, the porous structure did not change significantly. For $\mathrm{V}_{\text {mic }}$, the sample carbonized at $700^{\circ} \mathrm{C}$ exhibited the lower $\mathrm{V}_{\text {mic }}\left(0.016 \mathrm{~cm}^{3} / \mathrm{g}\right)$, while the $\mathrm{V}_{\text {mic }}$ increased slightly to $0.024-0.027 \mathrm{~cm}^{3} / \mathrm{g}$ for those carbonized over $800^{\circ} \mathrm{C}$, indicating that more micropores from the decomposition of PAN could be obtained at a higher temperature.

Figure 3(b) provides the variation of the mesopore size distribution of the samples prepared from different carbonization temperature. No peak could be observed for the sample carbonized at $700^{\circ} \mathrm{C}$, while an evident peak at $7.5 \mathrm{~nm}$ could be found for that at $800^{\circ} \mathrm{C}$. When the carbonization temperature reached $900{ }^{\circ} \mathrm{C}$, a broader peak at around $12.5 \mathrm{~nm}$ could be detected, which might be attributed to the agglomeration of nano-MnO particles at a higher temperature. This reflects that carbonization temperature is also an essential factor determining the porous structure of prepared carbon. As shown in TG analysis (Fig. 1), the last weight-loss stage of the mixture sample took place at around $860^{\circ} \mathrm{C}$, revealing that the decomposition of PAN was not completed before this temperature, which results in the low $\mathrm{V}_{\text {mic }}$ for that carbonized at $700^{\circ} \mathrm{C}$. Such poor microporous structure might block the $\mathrm{H}^{+}$ entering into the inner parts of carbon and accordingly, $\mathrm{MnO}$ would not be removed by acid washing, causing a poor mesoporous structure (Table 1 and Fig. $3 \mathrm{~b}$ ).

The effect of pre-oxidation temperature on the porous structure of prepared samples was also discussed (Table 1). Compared with the sample without pre-oxidation, the samples pre-oxidized at 180 and $200^{\circ} \mathrm{C}$ possessed a remarkably abundant porous structure, demonstrating that the pre-oxidation process could help the production of pores. Furthermore, with the increase of pre-oxidation temperature from 180 to $200^{\circ} \mathrm{C}$, their $\mathrm{S}_{\mathrm{BET}}$, $\mathrm{V}_{\text {tot }}$ and $\mathrm{V}_{\text {meso }}$ increased and then declined when the temperature was higher than $200^{\circ} \mathrm{C}$. Their mesopore size distributions are presented in Fig. 3(c). All peaks were emerged at $12.5 \mathrm{~nm}$, suggesting that the pre-oxidation temperature would not affect the particle size of generated nano-MnO. This might be ascribed to the higher decomposition temperature of $\mathrm{MnCO}_{3}\left(\sim 358^{\circ} \mathrm{C}\right)$ than the pre-oxidation temperature $\left(<240^{\circ} \mathrm{C}\right)$. However, their peak areas changed with the variation of pre-oxidation temperature, which might reflect that the pre-oxidation temperature could influence the carbon structure. As a result, this might affect the removal of MnO by acid washing. 

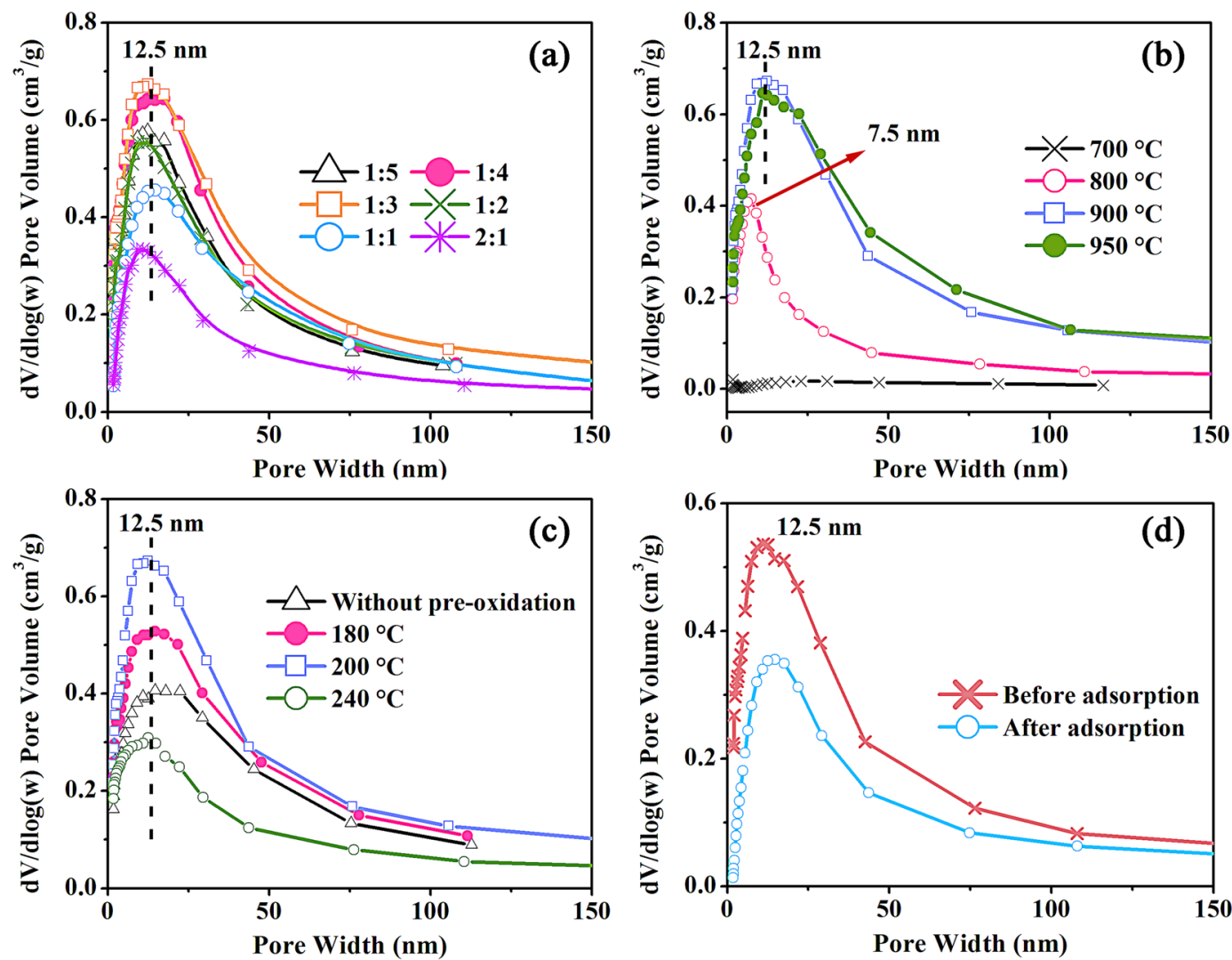

Figure 3. Mesopore size distribution of the samples prepared from different conditions (Legends represented the weight ratio of PAN and $\mathrm{MnO}(\mathbf{a})$, carbonization temperature (b), and pre-oxidation temperature (c), before and after adsorption of the mesopore carbon with the weight ratio of $1: 3$, carbonized at $900^{\circ} \mathrm{C}$ and pre-oxidized at $\left.200^{\circ} \mathrm{C}(\mathbf{d})\right)$.

It was reported that the pre-oxidation mainly occurred in amorphous region at low temperature $\left(<200^{\circ} \mathrm{C}\right)$, while the crystalline area started to be oxidized at high temperature $\left(>235^{\circ} \mathrm{C}\right)$, resulting in the transformation of chain to trapezoid structure with higher thermal stability ${ }^{27}$. For the templated method, such stable carbon structure could lead to a coating of MnO templates, increasing the difficulty in the removal of templates. Thus, higher pre-oxidation temperature could lead to a poor porous structure of prepared samples.

AR88 adsorption performance. The mesoporous carbon prepared from different conditions was adopted as the adsorbents for the removal of AR88 and their results are presented in Fig. 4. With the decrease of PAN and $\mathrm{MnO}$ weight ratios from 2:1 to 1:4, the adsorption capacities and removal efficiencies of the dye increased steadily from $167 \mathrm{mg} / \mathrm{g}$ and $53.53 \%$ to $309 \mathrm{mg} / \mathrm{g}$ and $99.76 \%$, respectively. When the carbonization temperature raised from 800 to $900^{\circ} \mathrm{C}$, the adsorption performance of the obtained sample was enhanced significantly. Furthermore, the samples with the pre-oxidation at 180 and $200^{\circ} \mathrm{C}$ presented higher adsorption capacities of AR8 than that without pre-oxidation. With the increase of pre-oxidation temperature from 180 to $200^{\circ} \mathrm{C}$, the adsorption capacities increased slightly and then dropped evidently for the sample with the pre-oxidation temperature at $240^{\circ} \mathrm{C}$. The results show that high adsorption capacity and removal efficiency of the dye was obtained for the sample with the weight ratio of 1:3, the pre-oxidation temperature at 200 and carbonization temperature at $900{ }^{\circ} \mathrm{C}$. Table 2 lists and compares the maximum adsorption capacity of AR88 on various adsorbents. The value of the maximum adsorption capacity determined from the Langmuir isotherm was $309 \mathrm{mg} \mathrm{g}^{-1}$, which was comparable to the published results in previous papers ${ }^{28-35}$. This result suggests that the PAN-mesoporous as adsorbent was suitable for the removal of AR88 from aqueous solution.

AR88 adsorption mechanisms. The relationship between adsorption capacity and surface chemistry. The elemental formation on the carbon was investigated by FTIR and XPS analysis. From the microstructure of the prepared sample (Fig. 5a), the mesoporous carbon presented the abundant and clearly visible porous structure. After the adsorption process, the surface of mesoporous carbon was covered and most tunnels were blocked, indicating the successful adsorption of AR88 molecules. As illustrated in FITR analysis (Fig. 5c), the bands emerged at $3700-3000,2925,2847,1705,1578$ and $1182 \mathrm{~cm}^{-1}$ could be found for the prepared samples, which belongs to the stretching vibration of $\mathrm{O}-\mathrm{H}$ from sugar, asymmetric stretching vibration of $\mathrm{CH}_{2}$, stretching vibration of $\mathrm{C}-\mathrm{H}$, stretching vibration of $\mathrm{C}=\mathrm{O}$, asymmetric stretching vibration of $\mathrm{COO}$ and stretching vibration of $\mathrm{C}-\mathrm{O}$. Moreover, the absorption band appeared at $1129 \mathrm{~cm}^{-1}$ could also be observed, indicating the existence of $\mathrm{C}-\mathrm{N}$ that came 

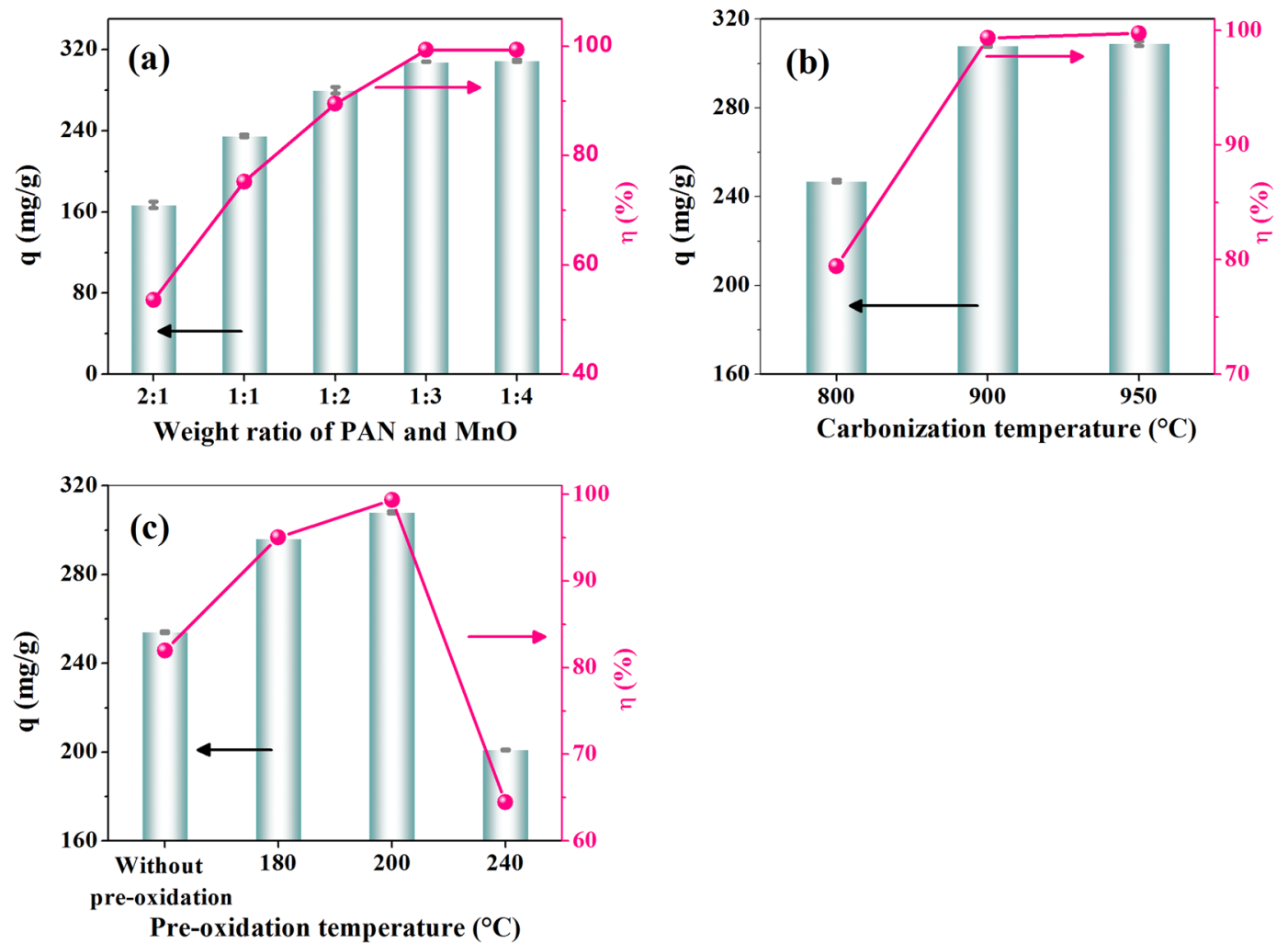

Figure 4. AR88 adsorption capacities of the samples prepared from different conditions (weight ratio of PAN and $\mathrm{MnO}(\mathbf{a})$, carbonization temperature (b), and pre-oxidation temperature (c). Error bars represent the standard deviation of triplicate experiments).

\begin{tabular}{|c|c|c|}
\hline Adsorbent & $q\left(\mathrm{mg} \mathrm{g}^{-1}\right)$ & Ref. \\
\hline PAN-mesoporous carbon & 309 & This study \\
\hline Activated carbon & 109 & 28 \\
\hline Multi-walled carbon nanotubes- $\mathrm{Fe}_{3} \mathrm{C}$ & 54.4 & 29 \\
\hline $\mathrm{ZnFe}_{2} \mathrm{O}_{4}$ & 111.1 & 30 \\
\hline Azolla filiculoides & 123.5 & 31 \\
\hline Anion exchange membrane & 227.1 & 32 \\
\hline Graphene aerogel/CaCO${ }_{3}$ composite & 1234 & 33 \\
\hline Fe@graphite nanocomposite & 41.8 & 34 \\
\hline Hollow mesoporous carbon nanospheres & 555.6 & 35 \\
\hline
\end{tabular}

Table 2. Comparison of the AR88 adsorption performance on various adsorbents.

from the transformation of $\mathrm{C} \equiv \mathrm{N}$ during the carbonization process. After AR88 adsorption of the carbon, the intensity of $\mathrm{C}=\mathrm{O}$ was weakened and the band of $\mathrm{C}-\mathrm{N}$ disappeared, implying that they could take part in the adsorption process. Moreover, the bands located at $1041,839,751$ and $685 \mathrm{~cm}^{-1}$ appeared, which were assigned to the stretching modes of $\mathrm{SO}_{3}$ in the sulfonate group, $\mathrm{S}-\mathrm{O}$ and C-S, respectively ${ }^{35}$. This might come from the sulfonic group in AR88 molecules that was adsorbed on the carbon surface.

The elemental contents obtained from XPS spectra of carbon pre-oxidized at different temperature are listed in Table 3. With the increase of pre-oxidation temperature, the relative contents of oxygen gradually increased, demonstrating that more oxygen atoms were introduced to the surface of the carbon matrix. On the contrast, the $\mathrm{N}$ contents decreased with the growing of pre-oxidation temperature, especially for that at $240^{\circ} \mathrm{C}$. This indicated that more $\mathrm{N}$ species was released at a relatively higher pre-oxidation temperature.

The high-resolution XPS spectra for $\mathrm{C} 1 \mathrm{~s}, \mathrm{O} 1 \mathrm{~s}$ and $\mathrm{N} 1 \mathrm{~s}$ of the samples are presented in Fig. 6 and the relative contents of each functional group calculated from their peak areas are summarized in Table 4 . The peaks of $\mathrm{C}$ 1s spectra with binding energy (BE) at $286 \sim 287,285 \sim 286$ and $\sim 284.6 \mathrm{eV}$ were associated with the C $=\mathrm{O}, \mathrm{C}-\mathrm{O}$ and graphitic $\mathrm{C}-\mathrm{C}$, respectively ${ }^{36}$. Four evident peaks could be detected in $\mathrm{N} 1 \mathrm{~s}$ spectra, corresponding with the pyridinic $\mathrm{N}(\mathrm{N}-6, \sim 399 \mathrm{eV})$, pyrrolic $\mathrm{N}(\mathrm{N}-5, \sim 400 \mathrm{eV})$, quaternary- $\mathrm{N}(\mathrm{N}-\mathrm{Q}, 401 \sim 403 \mathrm{eV})$ and oxidized-N $(\mathrm{N}-\mathrm{X}$, 403.5 and $406 \mathrm{eV})$, respectively ${ }^{37}$. 

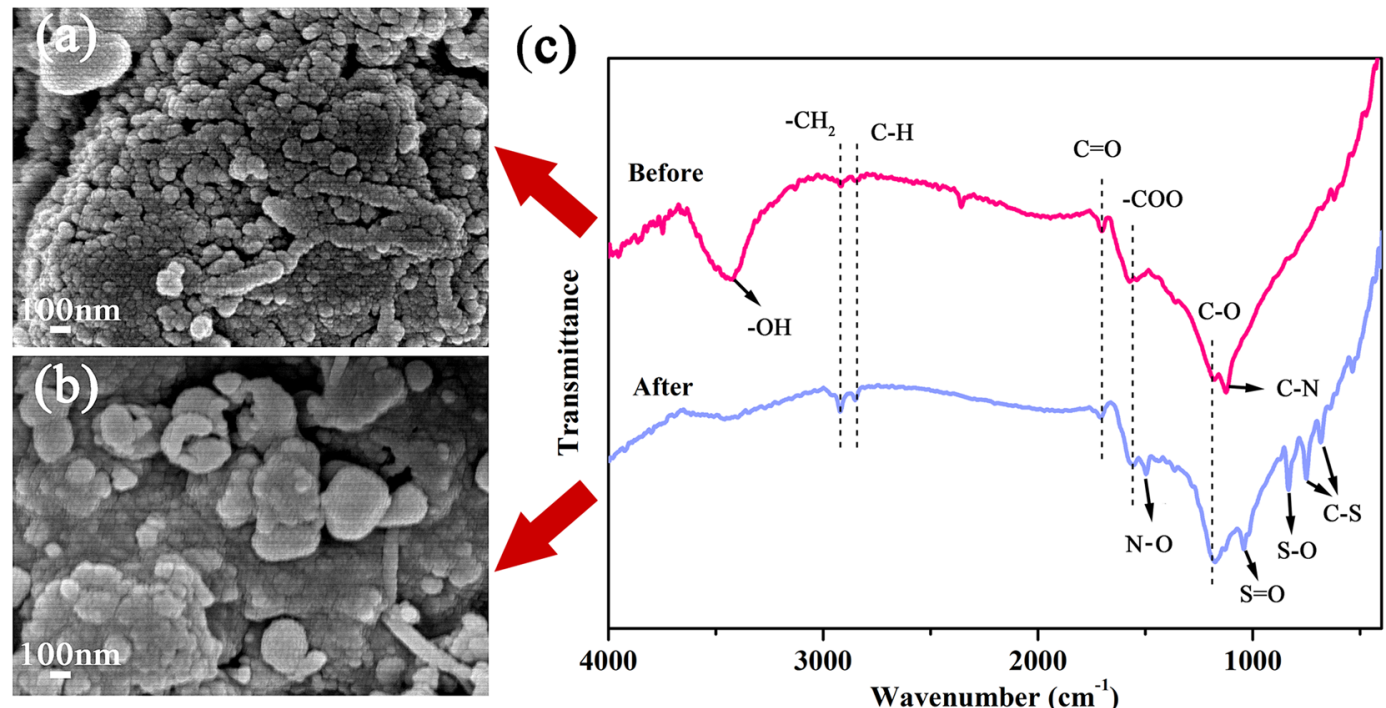

Figure 5. SEM images of prepared samples before (a) and after (b) adsorption of AR88; FTIR spectra (c) of the prepared sample (the weight ratio of $1: 3$, carbonized at $900^{\circ} \mathrm{C}$ and pre-oxidized at $200^{\circ} \mathrm{C}$ ) before and after adsorption of AR88.

\begin{tabular}{|l|l|l|l|l|}
\hline \multirow{2}{*}{$\begin{array}{l}\text { Pre-oxidation } \\
\text { temperature }\left({ }^{\circ} \mathrm{C}\right)\end{array}$} & \multicolumn{3}{|l|}{ Elemental analysis (\%) } & \multirow{2}{*}{ q/S } \\
\cline { 2 - 4 } & $\mathbf{C}$ & $\mathbf{O}$ & $\mathbf{N}$ & 0.702 \\
\hline- & & & & 0.674 \\
\hline 180 & 93.74 & 4.59 & 1.04 & 0.630 \\
\hline 200 & 93.90 & 4.80 & 1.01 & 0.596 \\
\hline 240 & 94.04 & 5.26 & 0.52 & \\
\hline
\end{tabular}

Table 3. Elemental contents and $\mathrm{q} / \mathrm{S}_{\mathrm{BET}}$ of carbon pre-oxidized at different temperature.

As shown in Fig. 6 and Table 4, after adsorption, the relative content of $\mathrm{C}=\mathrm{O}$ declined significantly from 5.75 to $0.00 \%$, revealing that it might be evolved in the adsorption process. It was reported that $\mathrm{C}=\mathrm{O}$ was a kind of Lewis basic group, which had a strong attraction for acid molecules by electrostatic interaction. After adsorption, the contents of N-6, N-5 and N-Q became lower than those before adsorption, while that of N-X increased significantly from $5.00 \%$ to $21.54 \%$. This indicates that N-6, N-5 and N-Q could participate in the reaction and converted to $\mathrm{N}-\mathrm{X}$ during the adsorption process. This phenomenon might be related to the occupation of basic functional groups (pyridine-N) during the adsorption process, which could attract phenolic hydroxyl and sulfonic group in AR88 by electrostatic interaction ${ }^{38}$. Normally, pyridine- $\mathrm{N}$ is bonded to two neighbouring $\mathrm{C}$ atoms with the location along with the edges of the carbon planes, which are considered as Lewis bases and readily interact with the acidic AR8 8 molecules ${ }^{39}$. According to Gong's work ${ }^{40}$, the nitrogen atom in pyridinic C-N group can form the strong hydrogen bonding interaction with dye molecule. The porous carbon was also detected using Raman analysis and related spectra were plotted in Fig. S3. The characteristic peaks located at approximately and $\mathrm{cm}$ can be assigned to $\mathrm{G}$ band (the in-phase vibration of the sample lattice) and D band (the disorder band $)^{41}$. In general, a smaller $\mathrm{D} / \mathrm{G}$ ratio of peak intensity reveals a perfect graphitic structure. The $\mathrm{D} / \mathrm{G}$ ratio was found to be 1.68 revealing a graphitic structure with disordered carbons was created in the mesoporous carbon after high-temperature carbonization, which could facilitate the formation of $\pi-\pi$ dispersion interaction between graphic $\mathrm{C}$ with the aromatic rings in AR88, leading to enhanced adsorption ${ }^{42}$.

The relationship between adsorption capacity and textural properties. Fig. S2(d) shows the $\mathrm{N}_{2}$ adsorption-desorption isotherm of the sample (with the weight ratio of $1: 3$, carbonized at $900^{\circ} \mathrm{C}$ and pre-oxidized at $200^{\circ} \mathrm{C}$ ) before and after adsorption of AR88. Compared with the fresh one, the sample after adsorption presented evidently a lower nitrogen adsorption capacity during all relative pressure range. Its textural properties after adsorption are listed in Table 1 . It can be seen that its $\mathrm{S}_{\mathrm{BET}}, \mathrm{V}_{\text {tot }}, \mathrm{V}_{\text {meso }}$ and $\mathrm{V}_{\text {mic }}$ were dramatically decreased compared with the sample before adsorption. As shown in Fig. 3(d), the sample after adsorption possessed similar mesopore size distribution as the fresh one, while the peak area was clearly lower. The results suggest that the mesopores of the carbon were occupied mostly by the AR88 molecules, resulting in the lower porosity of the carbon after adsorption.

In addition, the relationships between the AR88 adsorption capacities and the textural properties of prepared samples were investigated (Fig. S4), and their correlation coefficient $\left(\mathrm{R}^{2}\right)$ are listed in Table 5. It can be found that the overall $R^{2}$ of the adsorption capacity vs $S_{B E T}, V_{\text {tot }}$ and $V_{\text {meso }}$ was evidently higher than those of $V_{\text {mic }}$ for 


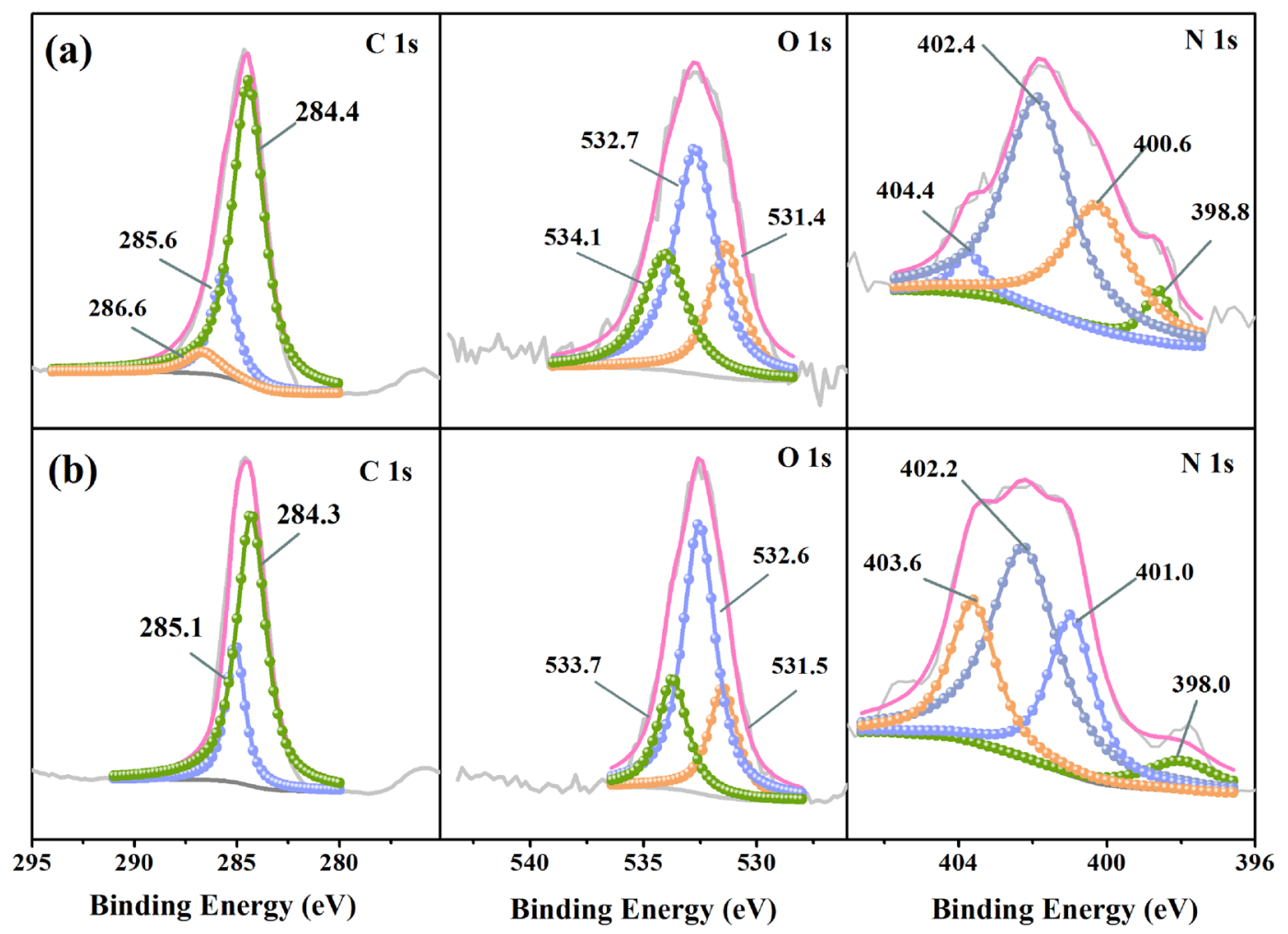

Figure 6. High-resolution XPS spectra for C $1 \mathrm{~s}, \mathrm{O} 1 \mathrm{~s}$ and $\mathrm{N} 1 \mathrm{~s}$ of the mesoporous carbon before (a) and after (b) adsorption of AR88.

\begin{tabular}{|l|l|l|}
\hline Binding Energy $(\mathbf{e V})$ & Before & After \\
\hline $\mathrm{C} 1 \mathrm{~s}$ & 88.30 & 81.97 \\
\hline $\mathrm{C}-\mathrm{C}(\sim 284.6)$ & 74.71 & 75.34 \\
\hline $\mathrm{C}-\mathrm{O}(285-286)$ & 19.54 & 24.66 \\
\hline $\mathrm{C}=\mathrm{O}(286-287)$ & 5.75 & - \\
\hline $\mathrm{O} 1 \mathrm{~s}$ & 9.50 & 16.34 \\
\hline $\mathrm{O}=\mathrm{C}(\sim 531.5)$ & 23.55 & 20.67 \\
\hline $\mathrm{O}-\mathrm{C}(\sim 532.6)$ & 49.93 & 58.27 \\
\hline $\mathrm{COOH}(\sim 533.7)$ & 26.52 & 21.06 \\
\hline $\mathrm{N} 1 \mathrm{~s}$ & 2.21 & 1.69 \\
\hline $\mathrm{N}-6$ & 5.77 & 4.29 \\
\hline $\mathrm{N}-5$ & 33.69 & 27.11 \\
\hline $\mathrm{N}-\mathrm{Q}$ & 55.54 & 47.06 \\
\hline $\mathrm{N}-\mathrm{X}$ & 5.00 & 21.54 \\
\hline
\end{tabular}

Table 4. Relative contents (\%) of each element and functional groups of the sample pre-oxidized at $200^{\circ} \mathrm{C}$ before and after adsorption.

all of the prepared carbons. This indicates that they played dominated roles in the adsorption of AR88, while $\mathrm{V}_{\text {mic }}$ had a negligible effect. AR88 was a kind of macromolecules with the molecular diameter at about $1.68 \mathrm{~nm}$. As reported in previous studies, the pores with the diameter 2 to 3 times larger than the adsorbate molecular diameter could allow the adsorbate diffusion easily ${ }^{43}$. The AR88 with macromolecules could not be allowed to enter into narrow pores of carbon $(<2 \mathrm{~nm})$. Thus, the abundant mesoporous structure of prepared carbon in this study was preferred for the adsorption of AR88. The AR88 adsorption capacities were dramatically affected by the textural properties of prepared mesoporous carbon. The $S_{\mathrm{BET}}$ of the samples from different pre-oxidation conditions had a relatively lower correlation with adsorption capacities (0.874), compared with those prepared at different weight ratios (0.982) and carbonization temperature (0.978). This demonstrates that there might be other factors affecting the AR88 adsorption, except for the porous structure of carbon. For a better understanding of the factors responsible for the adsorption performance beyond porous structure, the AR88 adsorption capacities of the carbon with different pre-oxidization temperatures were normalized by $S_{B E T}\left(q / S_{B E T}\right)$, and the results 


\begin{tabular}{|l|l|l|l|l|}
\hline \multirow{2}{*}{ Preparation condition } & \multicolumn{4}{|l|}{ Textural properties } \\
\cline { 2 - 5 } & $\mathbf{S}_{\text {BET }}$ & $\mathbf{V}_{\text {tot }}$ & $\mathbf{V}_{\text {mic }}$ & $\mathbf{V}_{\text {meso }}$ \\
\hline Weight ratio & 0.982 & 0.942 & 0.568 & 0.947 \\
\hline Carbonization temperature & 0.978 & 0.996 & 0.884 & 0.997 \\
\hline Pre-oxidation temperature & 0.874 & 0.954 & 0.073 & 0.957 \\
\hline Overall & 0.895 & 0.840 & 0.191 & 0.819 \\
\hline
\end{tabular}

Table 5. Correlation $\left(\mathrm{R}^{2}\right)$ between AR88 adsorption capacities and textural properties of prepared samples.

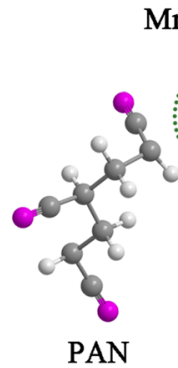

$\mathrm{MnCO}_{3}$ template

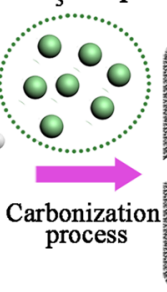

AN

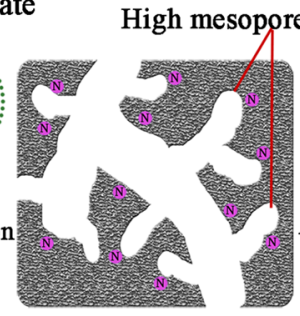

High mesopore ratio

Interface interaction

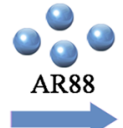
process
Capillary condensation

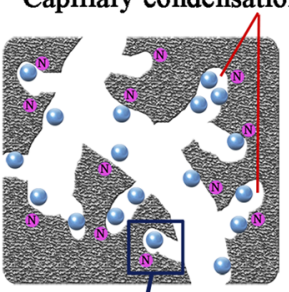

I

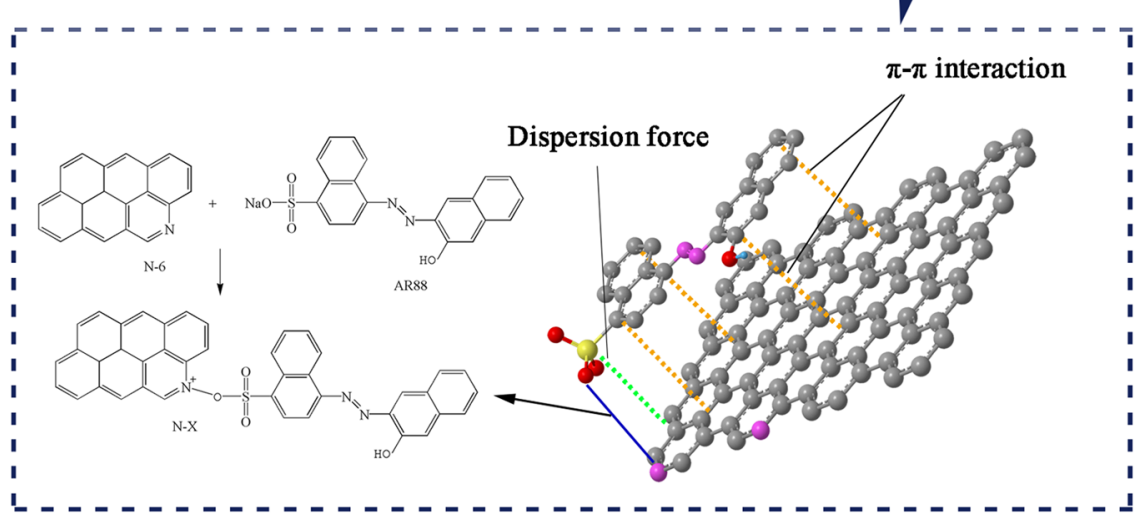

Figure 7. Schematic illustration showing the AR88 adsorption mechanism by mesoporous carbon: the capillary condensation effect of mesopores and the interactions between porous carbon and AR88.

are listed in Table 3. The sample without pre-oxidization presented the highest $\mathrm{q} / \mathrm{S}_{\mathrm{BET}}$ at 0.702 , while those with pre-oxidization had lower $\mathrm{q} / \mathrm{S}_{\mathrm{BET}}$ values. The sample pre-oxidized at $240^{\circ} \mathrm{C}$ exhibited the lowest value, i.e., only 0.596. This result presented a similar order with the $\mathrm{N}$ contents in each carbon (Table 3 ), suggesting that higher contents of $\mathrm{N}$ on the carbon surface might help its AR88 adsorption.

Combined with the results of FTIR and XPS, it can be assumed that both physical and chemical interaction could happen between the AR88 and prepared carbon. Considering these results, the possible adsorption mechanisms of AR8 8 molecules by mesoporous carbon can be proposed in Fig. 7. First, the rich mesopores in porous carbon enhance the capillary condensation, which facilitates the diffusion and adsorption of AR88 molecules. Besides, the AR88 adsorption could also be affected by the electrostatic interaction between acid AR88 molecules and basic groups on carbon surface (including $\mathrm{C}=\mathrm{O}$ and pyridine- $\mathrm{N}$ ), and $\pi-\pi$ dispersion interaction between aromatic rings of AR88 and carbon basal plane with the presence of $\mathrm{N}$ atoms.

Adsorption isotherm. To better understand the AR88 adsorption process by the prepared mesoporous carbon, the correlation between adsorption equilibrium concentration and the adsorption capacity for AR88 was evaluated at $25^{\circ} \mathrm{C}$. From the adsorption isotherm curve plotted in Fig. 8, the AR88 adsorption amount was enhanced gradually with increasing the equilibrium concentration and reached a plateau at a relatively high equilibrium value.

Adsorption isotherm could help understand the interaction between adsorbents and adsorbates, which is essential for the optimal utilization of adsorbents. Three isotherm models, i.e. Langmuir, Freundlich and Sips model, were applied to investigate the interaction of mesoporous carbon with AR88. The non-linear fitting of the three models is plotted in Fig. 8 and their parameters, together with $\mathrm{R}^{2}$, are given in Table 6 . The $\mathrm{R}^{2}$ of each model was in the order of Sips (0.989) $>$ Freundlich (0.987) $>$ Langmuir (0.922), demonstrating that Sips and Freundlich could provide a better description of the process of AR88 adsorption on the prepared mesoporous carbon. The isotherm curve presented a sustainable growth with the increase of $C_{e}$ and $q_{m}$ predicted by Sips model was $580.3 \mathrm{mg} / \mathrm{g}$, indicating that more AR88 could be adsorbed at higher initial concentrations. Furthermore, the $\gamma$ 


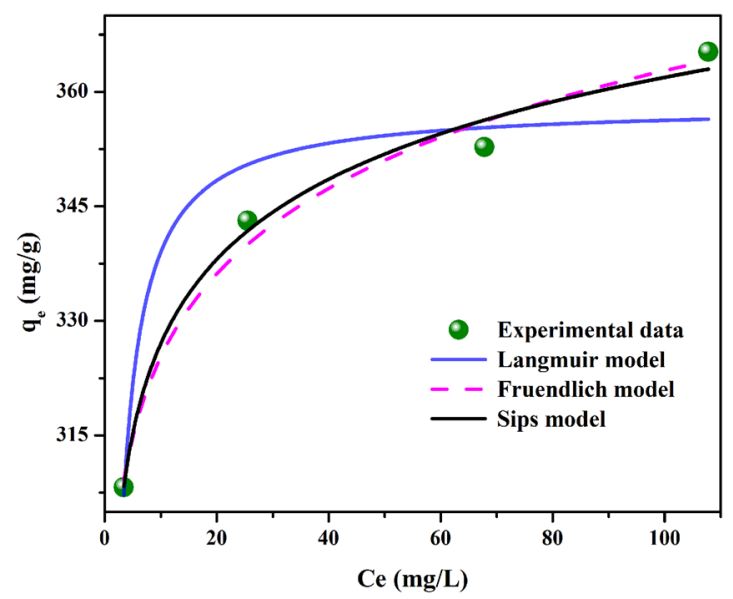

Figure 8. Non-linear fitting of Langmuir, Freundlich and Sips model for AR88 adsorption by mesoporous carbon.

\begin{tabular}{|c|c|c|c|}
\hline Model & Parameter & Value & $\mathbf{R}^{2}$ \\
\hline \multicolumn{4}{|l|}{ Isotherm } \\
\hline \multirow{2}{*}{ Langmuir } & $\mathrm{q}_{\mathrm{m}}(\mathrm{mg} / \mathrm{g})$ & 358.3 & \multirow{2}{*}{0.922} \\
\hline & $\mathrm{K}_{\mathrm{L}}(\mathrm{L} / \mathrm{mg})$ & 0.570 & \\
\hline \multirow{2}{*}{ Fruendlich } & $\mathrm{K}_{\mathrm{F}}\left((\mathrm{mg} / \mathrm{g}) /(\mathrm{L} / \mathrm{mg})^{1 / \mathrm{n}}\right)$ & 291.6 & \multirow{2}{*}{0.987} \\
\hline & $1 / \mathrm{n}$ & 0.047 & \\
\hline \multirow{3}{*}{ Sips } & $\mathrm{q}_{\mathrm{m}}(\mathrm{mg} / \mathrm{g})$ & 580.3 & \multirow{3}{*}{0.989} \\
\hline & $\mathrm{K}_{\mathrm{S}}(\mathrm{mL} / \mathrm{mg})$ & 1.183 & \\
\hline & $\gamma$ & 0.100 & \\
\hline \multicolumn{4}{|l|}{ Kinetic } \\
\hline \multirow{2}{*}{ Pseudo-1st-order } & $\mathrm{K}_{1}\left(\mathrm{~min}^{-1}\right)$ & 0.092 & \multirow{2}{*}{0.989} \\
\hline & $\mathrm{q}_{\mathrm{e}}(\mathrm{mg} / \mathrm{g})$ & 33.4 & \\
\hline \multirow{2}{*}{ Pseudo-2nd-order } & $\mathrm{K}_{2}(\mathrm{~g} /(\mathrm{mg} \cdot \mathrm{min}))$ & 0.009 & \multirow{2}{*}{1.000} \\
\hline & $\mathrm{q}_{\mathrm{e}}(\mathrm{mg} / \mathrm{g})$ & 312.5 & \\
\hline \multirow{6}{*}{ Intraparticle diffusion } & $\mathrm{K}_{\mathrm{p} 1}\left(\mathrm{mg} / \mathrm{g} \cdot \mathrm{min}^{0.5}\right)$ & 7.29 & \multirow{2}{*}{0.994} \\
\hline & $\mathrm{C}_{1}$ & 274.5 & \\
\hline & $\mathrm{K}_{\mathrm{p} 2}\left(\mathrm{mg} / \mathrm{g} \cdot \mathrm{min}^{0.5}\right)$ & 2.89 & \multirow{2}{*}{0.964} \\
\hline & $\mathrm{C}_{2}$ & 292.2 & \\
\hline & $\mathrm{K}_{\mathrm{p} 3}\left(\mathrm{mg} / \mathrm{g} \cdot \mathrm{min}^{0.5}\right)$ & 0.18 & \multirow{2}{*}{0.753} \\
\hline & $\mathrm{C}_{3}$ & 309.7 & \\
\hline
\end{tabular}

Table 6. Results of isotherm and kinetic model fitting.

value was only 0.1 , demonstrating that the adsorption process could not belong to monolayer sorption and some interactions might occur among adsorbed AR88 molecules.

Kinetics study. Figure 9 shows the AR88 adsorption capacity $\left(\mathrm{q}_{\mathrm{t}}\right)$ by prepared mesoporous carbon against time. It can be seen that the adsorption capacity increased dramatically to $290 \mathrm{mg} / \mathrm{g}$ within the initial $5 \mathrm{~min}$, indicating that large quantities of AR8 molecule were rapidly uptake by prepared carbon. Subsequently, the increase of adsorption capacity was slow down and no more AR8 could be adsorbed after $45 \mathrm{~min}$, suggesting that the adsorption equilibrium was approached.

The pseudo $1^{\text {st }}$ order, pseudo $2^{\text {nd }}$ order and intrparticle diffusion models were applied to simulate the adsorption process, whose fitting curves are presented in Fig. 9. It can be seen that the adsorption rate was high at the initial stage and gradually became lower after $5 \mathrm{~min}$ and the uptake of AR8 turned to be saturated after $30 \mathrm{~min}$, revealing that the adsorption process finished rapidly. This might be due to the abundant mesoporous structure in carbon, which could decrease the diffusion resistance of AR88 molecules. The parameters for both pseudo- ${ }^{\text {st }}$-order and pseudo- $2^{\text {nd }}$-order are presented in Table 6 . According to $\mathrm{R}^{2}$ value, the fitting dgree of pseudo- $2^{\text {nd }}$-order model $\left(\mathrm{R}^{2}=1.0\right)$ was higher than that of pseudo- $1^{\text {st }}$-order $\left(\mathrm{R}^{2}=0.989\right)$, indicating that the pseudo- $2^{\text {nd }}$-order model could describe the adsorption process better. Pseudo- $2^{\text {nd }}$-order model assumes that the adsorption rate is determined by the square of the vacant site number that has not been occupied by adsorbents and the adsorption process was controlled by the chemical effect. The desirable fitting of pseudo- $2^{\text {nd }}$-order to experimental data suggested that the adsorption process could belong to chemisorption and the adsorption 

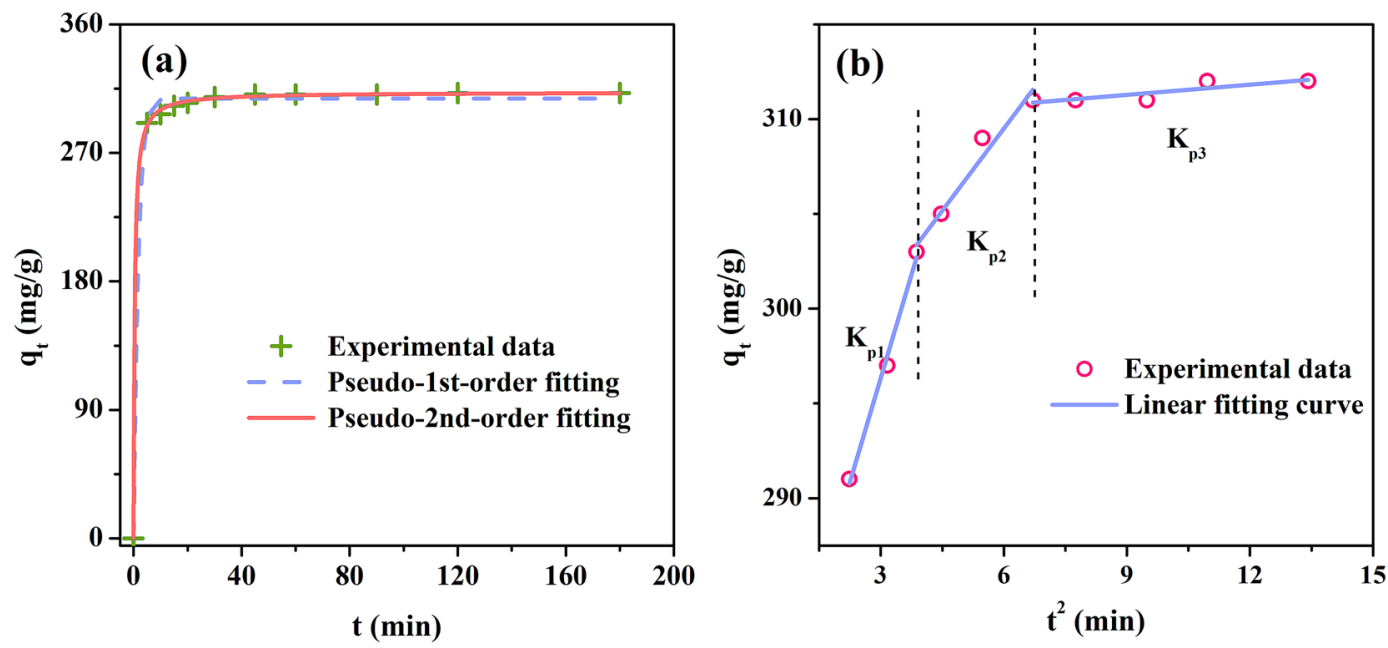

Figure 9. Non-linear fitting of pseudo- $1^{\text {st }}$-order and pseudo- $2^{\text {nd }}$-order (a) for AR88 adsorption by mesoporous carbon, and (b) linear fitting of the intraparticle diffusion model.

involves the electron transfer or/and sharing. The results are in a good agreement with the variation of surface chemistry before and after adsorption (Figs. 5 and 6).

The linear fitting of the intraparticle diffusion model to experimental data is depicted in Fig. 9(b), in which three linear stages could be observed, with the slopes as $\mathrm{K}_{\mathrm{p} 1}, \mathrm{~K}_{\mathrm{p} 2}$ and $\mathrm{K}_{\mathrm{p} 3}$, respectively. The parameters, including the slopes, intercept and $\mathrm{R}^{2}$ values, are listed in Table 6. It could be seen that the slope of the three stages was in the order of $\mathrm{K}_{\mathrm{p} 1}>\mathrm{K}_{\mathrm{p} 2}>\mathrm{K}_{\mathrm{p} 3}$, indicating that the equilibrium was gradually obtained. The first and sharp liner portion of plots reveals that the boundary layer diffusion limits the AR88 adsorption. The last two gentle stages indicate that the occurrence of intraparticle diffusion is the adsorption limiting step ${ }^{44}$. In addition, all C values were relatively high and far from the origin, demonstrating that the intraparticle diffusion was not the sole rate-controlling step, which was ascribed to the rich mesoporous structure in prepared carbon that could effectively decrease the diffusion resistance of AR88.

In summary, the nitrogen-containing graphitic mesoporous carbon could be successfully prepared by using PAN as both carbon and nitrogen resources and $\mathrm{MnCO}_{3}$ as template and catalyst precursors. The graphitized degree of prepared carbon could be evidently elevated via the introduction of $\mathrm{MnCO}_{3}$. The weight ratios of carbon and template precursor, carbonization temperature and pre-oxidation temperature played vital roles for the textural properties of prepared mesoporous carbon, which affect significantly their AR88 adsorption behavior. Moreover, the carbon- and nitrogen-containing groups on the surface of mesoporous carbon also had an influence on the adsorption capacity of AR88. The rich graphic carbon tended to form the $\pi-\pi$ dispersion interaction with the aromatic rings in AR88. which contributed to the adsorption process. The $\pi-\pi$ dispersion interaction and electrostatic interaction Sips model could give a better description for the AR8 adsorption by the prepared mesoporous carbon, with the $\gamma$ value at 0.01 , suggesting that the adsorbent surface might not be homogenous or/and there might be some interactions among adsorbates. Furthermore, the pseudo $2^{\text {nd }}$-order model fitted the experimental data better than the pseudo $1^{\text {st }}$-order model, confirming the chemisorption of AR88. The intraparticle diffusion model certified that the intraparticle diffusion was not the rate-determining step of adsorption, which was attributed to the abundant mesoporous structure in the prepared mesoporous carbon.

\section{Methods}

Materials. $\mathrm{PAN}, \mathrm{MnCO}_{3}, \mathrm{H}_{2} \mathrm{SO}_{4}$ were provided from Kelong chemical reagent factory, Chengdu, China. AR88 was purchased from Aladdin Chemistry Co., Ltd. All reagents were used in this study without further treatment.

Preparation of mesoporous carbon. The received PAN and $\mathrm{MnCO}_{3}$ with particle size below 200 mesh were adequately mixed at specified weight ratios at $2: 1,1: 1,1: 2,1: 3,1: 4$ and 1:5, respectively. The mixtures were firstly pre-oxidized at $200^{\circ} \mathrm{C}$ for $60 \mathrm{~min}$ in air and subsequently heated up to $900^{\circ} \mathrm{C}$ with a heating rate of $5{ }^{\circ} \mathrm{C} /$ min under a nitrogen atmosphere using a horizontal tube furnace. After $1 \mathrm{~h}$ of carbonization, the samples were cooled down to room temperature, followed by acid washing using $1.8 \mathrm{~mol} / \mathrm{L}$ of $\mathrm{H}_{2} \mathrm{SO}_{4}$ solution for several times until the concentrations of $\mathrm{Mn}^{2+}$ lower than $0.01 \mathrm{mg} / \mathrm{L}$. Finally, samples were washed with distilled water to neutral and dried at $105^{\circ} \mathrm{C}$ overnight. The related preparation route is illustrated in Fig. 10. Furthermore, the effects of the carbonization temperature $\left(700,800,900\right.$ and $\left.950^{\circ} \mathrm{C}\right)$ and pre-oxidation $\left(180,200\right.$ and $\left.240^{\circ} \mathrm{C}\right)$ on the prepared mesoporous carbon were also evaluated.

Characterization of mesoporous carbon. Thermogravimetric method was adopted to simulate the carbonization process of PAN. The received PAN, $\mathrm{MnCO}_{3}$ powder and their mixture with and without pre-oxidation at $200^{\circ} \mathrm{C}$ for $1 \mathrm{~h}$ were transferred into a TG analyzer (Ta-50, Shimadzu, Japan) and heated to $1000^{\circ} \mathrm{C}$ under $\mathrm{N}_{2}$ 


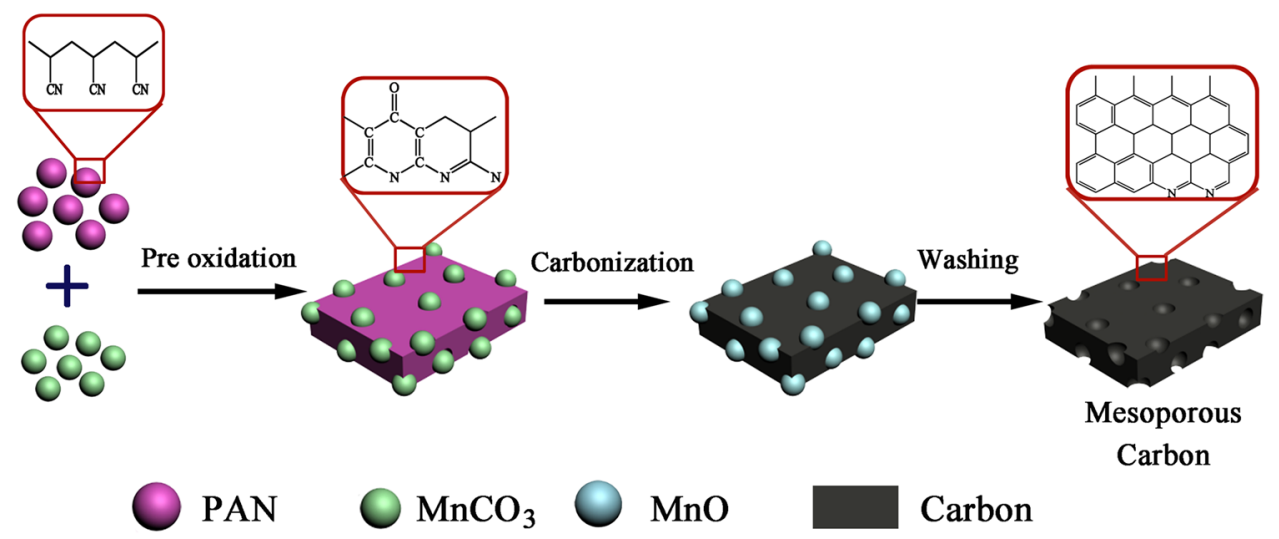

Figure 10. Schematic illustration showing the preparation route of PAN-mesoporous carbon.

atmosphere with a heating rate of $5^{\circ} \mathrm{C} / \mathrm{min}$. The transformation of $\mathrm{Mn}$ and the graphitization degree of prepared carbon were performed on an X-ray diffractometry (X-Pert PRO MPD, PANalytical B.V., Netherland), whose patterns were recorded with a resolution of 0.026 in the $2 \theta$ ranging from $10^{\circ}$ to $80^{\circ}$. And the interplanar spacing (d) of graphite carbon was calculated from Bragg's law. The porous structure of prepared carbons was characterized by using high-resolution transmission electron microscope (HRTEM) (Libra 200 FE, ZEISS, Germany). $\mathrm{N}_{2}$ adsorption-desorption method was applied for analyzing the porous structure of prepared mesoporous carbon using a surface area analyzer (ASAP2460, Micromeritics, USA). Before measurement, all carbons were degassed at $250^{\circ} \mathrm{C}$ for $8 \mathrm{~h}$ to remove volatile impurities. The BET surface area was determined using the Brunauer-Emmett-Teller (BET) equation in the relative pressure ranging from 0.05 to 0.35 . The microporous volume $\left(\mathrm{V}_{\text {mic }}\right)$ and total porous volume $\left(\mathrm{V}_{\text {tot }}\right)$ were calculated from the $\mathrm{t}$-plot method, while the $\mathrm{V}_{\text {meso }}$ and the mesopore size distribution were obtained from the BJH model. The surface chemistry of mesoporous carbon was characterized by Fourier transform infrared (FITR) spectroscopy (Nicolet 6700, Thermo Scientific, USA), X-ray photoelectron spectroscopy (XSAM800, KRATOS, UK) and Raman spectroscopy (HORIBA Jobin Yvon). For FTIR analysis, the dried carbon was mixed with $\mathrm{KBr}$ powder adequately and then pressed into a disk with a thickness of $0.8 \mathrm{~mm}$. The FTIR spectra were recorded with a step size of $2 \mathrm{~cm}^{-1}$ in the scanning from 4000 to $400 \mathrm{~cm}^{-1}$. XPS analysis was performed at a pressure of $10^{-7} \mathrm{~Pa}$ using a monochromatic $\mathrm{Al} \mathrm{K} \alpha \mathrm{X}$-ray source. The XPS Peaks software was used for data analyzing and all spectra curves were peak fitted with Gaussian-Lorentzian convoluted functions and Shirley's background. Raman tests were carried out using Labram HR spectrometer at laser excitation of $532 \mathrm{~nm}$ and the power of $1 \mathrm{~mW}$.

AR88 adsorption experiments. Prepared carbons with different template contents, carbonization temperature and pre-oxidation temperature were adopted as the adsorbents for the removal of AR88, which was performed using $500 \mathrm{~mL}$ of Erlenmeyer flasks at $25^{\circ} \mathrm{C} .250 \mathrm{~mL}$ of AR88 solutions $(250 \mathrm{mg} / \mathrm{L})$ and $0.2 \mathrm{~g}$ of carbon were added into the flasks and then they were agitated at $180 \mathrm{rpm}$ in a thermostatic shaker for $30 \mathrm{~min}$. The adsorption capacities of the adsorbents were obtained from the absorbance of AR88 solutions before and after adsorption at a wavelength of $503 \mathrm{~nm}$. The adsorption capacity and removal efficiency were calculated from Eqs. (1) and (2), respectively:

$$
\begin{gathered}
\mathrm{q}=\frac{\left(\mathrm{C}_{0}-C_{\mathrm{e}}\right) \times V}{\mathrm{~W}} \\
\eta=\frac{\mathrm{C}_{0}-C_{\mathrm{e}}}{\mathrm{C}_{0}} \times 100 \%
\end{gathered}
$$

where $\mathrm{q}(\mathrm{mg} / \mathrm{g})$ is the adsorption capacity, $\mathrm{C}_{0}$ is the initial concentration of $\mathrm{AR} 88, \mathrm{C}_{\mathrm{e}}$ is the equilibrium concentration ( $\mathrm{mg} / \mathrm{g}), \mathrm{V}$ is the volume of the AR88 solution, $\mathrm{W}(\mathrm{g})$ is the weight of adsorbent, and $\eta(\%)$ is the removal efficiency. All experiments were carried out in triplicate at the same time.

Adsorption isotherm. Three adsorption isotherms, including Langmuir, Freundlich and Sips model, were applied to explain the relationship between adsorbent and adsorbate and provide basic data to evaluate the adsorption process on practical application. Five different initial concentrations (150, 200, 250, 300 and $400 \mathrm{mg} / \mathrm{L})$ were adopted for isotherm analysis. Langmuir model was an empirical equation summarized from large quantities of experiments, which was widely investigated in wastewater adsorption treatment. Four assumptions were proposed for Langmuir model: First, adsorbates can only be adsorbed on the surface of adsorbents in monomolecular type; Second, the effects of the surface are even and each adsorption center have same energy; Third, no interaction exists among adsorbed molecules; Fourth, the dynamic balance of adsorption-desorption can be realized at some condition. The Langmuir equation is given in Eq. (3): 


$$
\mathrm{q}_{\mathrm{e}}=\frac{\mathrm{q}_{\mathrm{m}} \mathrm{K}_{\mathrm{L}} \mathrm{C}_{\mathrm{e}}}{1+K_{\mathrm{L}} \mathrm{C}_{\mathrm{e}}}
$$

where $\mathrm{q}_{\mathrm{e}}$ is the equilibrium adsorption capacity, $\mathrm{C}_{\mathrm{e}}(\mathrm{mg} / \mathrm{L})$ is the equilibrium concentration, $\mathrm{q}_{\mathrm{m}}(\mathrm{mg} / \mathrm{g})$ is the theoretical maximum adsorption capacity, and $\mathrm{b}(\mathrm{mg} / \mathrm{L})$ is the Langmuir constant related to the free energy of adsorption ${ }^{45}$. A higher $\mathrm{b}$ value confirms the high interaction stability between adsorbents and adsorbates. Freundlich model takes the heterogeneity of the adsorbent surface into account. It assumes that the adsorbent surface is not homogeneous and the adsorption is in multi-layer type. Moreover, several interactions can exist among adsorbate molecules. The Freundlich equation is presented in Eq. (4):

$$
\mathrm{q}_{\mathrm{e}}=K_{\mathrm{f}} \mathrm{C}_{\mathrm{e}}^{1 / n}
$$

where $\mathrm{K}_{\mathrm{f}}\left((\mathrm{mg} / \mathrm{g}) /(\mathrm{L} / \mathrm{mg})^{1 / \mathrm{n}}\right)$ is the constant related to the adsorption capacity and $\mathrm{n}$ represents the process intensity.

Sips model is the modified Langmuir model, whose equation is in Eq. (5):

$$
\mathrm{q}_{\mathrm{e}}=q_{\mathrm{m}} \frac{\left(K_{\mathrm{S}} \mathrm{C}_{\mathrm{e}}\right)^{\gamma}}{1+\left(K_{\mathrm{S}} \mathrm{C}_{\mathrm{e}}\right)^{\gamma}}
$$

where $\mathrm{K}_{\mathrm{S}}(\mathrm{mL} / \mathrm{mg})$ is the Sips isotherm constant and $\gamma$ (dimensionless) is the Sips exponent ${ }^{46}$. For Sips model, a parameter $\gamma$ was proposed to identify the homogeneity of adsorbent surface, thus it could be regarded as the combination of Langmuir model and Freundlich model. Once the value of $\gamma$ is 1 , the equation is equal to Langmuir model, proving the surface of adsorbent was homogenous ${ }^{47}$.

Kinetics study. Adsorption kinetics could help understand the adsorption mechanism and rate of mesoporous carbon, which is an important method to investigate the mass transfer process of adsorption. $0.2 \mathrm{~g}$ mesoporous carbon was added into $250 \mathrm{~mL}$ of $250 \mathrm{mg} / \mathrm{L}$ AR88 solution and the adsorption capacity was measured every five minutes. Three mathematical models, including pseudo-first-order, pseudo-second-order and intraparticle diffusion equation, were used to describe the experimental data of adsorption kinetics. The pseudo-first-order model is represented in Eq. (6):

$$
\ln \left(\mathrm{q}_{\mathrm{e}}-\mathrm{q}_{\mathrm{t}}\right)=\ln \mathrm{q}_{\mathrm{e}}-K_{\mathrm{l}} \mathrm{t}
$$

where $\mathrm{q}_{\mathrm{e}}(\mathrm{mg} / \mathrm{g})$ and $\mathrm{q}_{\mathrm{t}}(\mathrm{mg} / \mathrm{g})$ are the amounts of AR88 adsorbed at equilibrium and time $\mathrm{t}(\mathrm{min})$, respectively, while $K_{1}\left(\min ^{-1}\right)$ is the rate constant. The $K_{1}$ value was obtained from the slope of $\ln \left(\mathrm{q}_{\mathrm{e}}-\mathrm{q}_{\mathrm{t}}\right)$ vs $\mathrm{t}$.

The pseudo-second-order model was expressed by the Eq. (7) presented as follows:

$$
\frac{\mathrm{t}}{\mathrm{q}_{\mathrm{t}}}=\frac{1}{\mathrm{~K}_{2} \mathrm{q}_{\mathrm{e}}^{2}}+\frac{\mathrm{t}}{\mathrm{q}_{\mathrm{e}}}
$$

where $\mathrm{K}_{2}(\mathrm{~g} /(\mathrm{mg} \cdot \mathrm{min}))$ is the rate constant pseudo-second-order kinetic model, which was calculated from the slope of the linear plots $\mathrm{t} / \mathrm{q}_{\mathrm{t}}$ against $\mathrm{t}$.

The intraparticle diffusion models could describe the internal particle diffusion effect, whose equation was presented as Eq. (8):

$$
\mathrm{q}_{\mathrm{t}}=K_{\mathrm{p}} \mathrm{t}^{0.5}+C
$$

where $\mathrm{K}_{\mathrm{p}}(\mathrm{mg} /(\mathrm{g} \cdot \mathrm{min}))$ is the intra-particle diffusion rate constant. $\mathrm{K}_{\mathrm{p}}$ and C were the slope and intercept of the linear plots of $\mathrm{q}_{\mathrm{t}}$ to $\mathrm{t}^{0.5}$, respectively.

Received: 15 November 2019; Accepted: 19 December 2019;

Published online: 28 January 2020

\section{References}

1. Kumar, A. N., Reddy, C. N. \& Mohan, S. V. Biomineralization of azo dye bearing wastewater in periodic discontinuous batch reactor: Effect of microaerophilic conditions on treatment efficiency. Bioresource Technol. 188, 56-64 (2015).

2. Benzigar, M. R. et al. Recent advances in functionalized micro and mesoporous carbon materials: synthesis and applications. Chem. Soc. Rev. 47, 2680-2721, https://doi.org/10.1039/c7cs00787f (2018)

3. Liew, R. K. et al. Microwave pyrolysis with $\mathrm{KOH} / \mathrm{NaOH}$ mixture activation: A new approach to produce micro-mesoporous activated carbon for textile dye adsorption. Bioresource Technol. 266, 1-10, https://doi.org/10.1016/j.biortech.2018.06.051 (2018).

4. Ma, J. Q., Yang, Q. F., Wen, Y. Z. \& Liu, W. P. Fe-g-C3N4/graphitized mesoporous carbon composite as an effective Fenton-like catalyst in a wide $\mathrm{pH}$ range. Appl. Catal. B-Environ. 201, 232-240, https://doi.org/10.1016/j.apcatb.2016.08.048 (2017).

5. Ahmad, Z. U. et al. Neodymium embedded ordered mesoporous carbon (OMC) for enhanced adsorption of sunset yellow: Characterizations, adsorption study and adsorption mechanism. Chem. Eng. J. 359, 814-826, https://doi.org/10.1016/j. cej.2018.11.174 (2019).

6. Zhang, X. L., Lin, Q. L., Luo, S. Y., Ruan, K. Z. \& Peng, K. P. Preparation of novel oxidized mesoporous carbon with excellent adsorption performance for removal of malachite green and lead ion. Appl. Surf. Sci. 442, 322-331, https://doi.org/10.1016/j. apsusc.2018.02.148 (2018).

7. Silva, T. L. et al. Mesoporous activated carbon fibers synthesized from denim fabric waste: Efficient adsorbents for removal of textile dye from aqueous solutions. J. Clean Prod. 171, 482-490, https://doi.org/10.1016/j.jclepro.2017.10.034 (2018).

8. Hao, G. P., Li, W. C., Wang, S., Zhang, S. \& Lu, A. H. Tubular structured ordered mesoporous carbon as an efficient sorbent for the removal of dyes from aqueous solutions. Carbon 48, 3330-3339 (2010). 
9. Enterría, M. \& Figueiredo, J. L. Nanostructured mesoporous carbons: Tuning texture and surface chemistry. Carbon 108, 79-102 (2016).

10. Jiang, T. et al. A novel sulfur-nitrogen dual doped ordered mesoporous carbon electrocatalyst for efficient oxygen reduction reaction. Appl. Catal. B Environ. 189, 1-11 (2016).

11. Goscianska, J., Marciniak, M. \& Pietrzak, R. Mesoporous carbons modified with lanthanum(III) chloride for methyl orange adsorption. Chem. Eng. J. 247, 258-264 (2014).

12. Lian, F. et al. One-step synthesis of a novel N-doped microporous biochar derived from crop straws with high dye adsorption capacity. J. Environ.l Manage. 176, 61-68 (2016).

13. He, C. \& Hu, X. Anionic Dye Adsorption on Chemically Modified Ordered Mesoporous Carbons. Ind. Eng. Chem. Res 50, 14070-14083 (2011).

14. Jiao, Y. et al. Synthesis of benzxazine-based nitrogen-doped mesoporous carbon spheres for methyl orange dye adsorption. J. Porous Mater. 24, 1-10 (2017).

15. Jiang, X., Xiang, X., Peng, S. \& Hou, L. Facile preparation of nitrogen-doped activated mesoporous carbon aerogel from chitosan for methyl orange adsorption from aqueous solution. Cellulose 26, 4515-4527, https://doi.org/10.1007/s10570-019-02368-2 (2019).

16. Chen, Y. et al. Hollow Nanotubes of N-Doped Carbon on CoS. Angew. Chem. 128, 16063-16066 (2016).

17. Gang, L., Li, X., Ganesan, P. \& Popov, B. N. Development of non-precious metal oxygen-reduction catalysts for PEM fuel cells based on N-doped ordered porous carbon. Appl. Catal. B Environ. 93, 156-165 (2009).

18. Yi, S., Chao, W., Zhen, F., Kuang, Y. \& Chen, J. Catalytic graphitization of PAN-based carbon fibers by spontaneously deposited manganese oxides. Transit. Metal Chem. 34, 559-563 (2009).

19. Jinjun, L. et al. Porous graphitized carbon for adsorptive removal of benzene and the electrothermal regeneration. Environ. Sci. Technol. 46, 12648 (2012).

20. Hou, W. et al. Synthesis and applications of novel graphitic carbon nitride/metal-organic frameworks mesoporous photocatalyst for dyes removal. Appl. Catal. B Environ. 174-175, 445-454 (2015).

21. Gu, L., Wang, J., Zou, Z. \& Han, X. Graphitic-C(3)N(4)-hybridized TiO(2) nanosheets with reactive $\{001\}$ facets to enhance the UV- and visible-light photocatalytic activity. J. Hazard. Mater. 268, 216-223 (2014).

22. Song, C., Wang, T., Qiu, Y., Qiu, J. \& Cheng, H. Effect of carbonization atmosphere on the structure changes of PAN carbon membranes. J. Porous Mater. 16, 197-203 (2009).

23. Surianarayanan, M., Uchida, T. \& Wakakura, M. Evolved gases by simultaneous TG-MS technique and associated thermal hazard in drying of polyacrylonitrile. J. Loss Prevent. Proc. Ind. 11, 99-108 (1998).

24. Bing, Z. et al. Modification of the desalination property of PAN-based nanofiltration membranes by a preoxidation method. Desalination 357, 208-214 (2015).

25. Zhao, J. et al. New understanding on the reaction pathways of the polyacrylonitrile copolymer fiber pre-oxidation: online tracking by two-dimensional correlation FTIR spectroscopy. RSC Adv. 6, 10.1039.C1035RA24320C (2016).

26. Ōya, A. \& Marsh, H. Phenomena of catalytic graphitization. J. Mater. Sci. 17, 309-322 (1982).

27. Sevilla, M. \& Fuertes, A. B. Catalytic graphitization of templated mesoporous carbons. Carbon 44, 468-474 (2006).

28. Mohan, S. V., Sailaja, P., Srimurali, M. \& Karthikeyan, J. Color removal of monoazo acid dye from aqueous solution by adsorption and chemical coagulation. Environ. Eng. Policy 1, 149-154 (1998).

29. Konicki, W., Pełech, I., Mijowska, E. \& Jasińska, I. Adsorption Kinetics of Acid Dye Acid Red 88 onto Magnetic Multi-Walled Carbon Nanotubes-Fe3C Nanocomposite. CLEAN - Soil, Air, Water 42, 284-294, https://doi.org/10.1002/clen.201200458 (2014).

30. Konicki, W., Sibera, D., Mijowska, E., Lendzion-Bieluń, Z. \& Narkiewicz, U. Equilibrium and kinetic studies on acid dye Acid Red 88 adsorption by magnetic ZnFe2O4 spinel ferrite nanoparticles. J. Colloid Interf. Sci. 398, 152-160, https://doi.org/10.1016/j. jcis.2013.02.021 (2013).

31. Padmesh, T. V. N., Vijayaraghavan, K., Sekaran, G. \& Velan, M. Batch and column studies on biosorption of acid dyes on fresh water macro alga Azolla filiculoides. J. Hazard. Mater. 125, 121-129, https://doi.org/10.1016/j.jhazmat.2005.05.014 (2005).

32. Xing, T., Kai, H. \& Chen, G. Study of adsorption and desorption performance of acid dyes on anion exchange membrane. Color. Technol. 128, 295-299, https://doi.org/10.1111/j.1478-4408.2012.00378.x (2012).

33. Arsalani, N., Nasiri, R. \& Zarei, M. Synthesis of magnetic 3D graphene decorated with CaCO 3 for anionic azo dye removal from aqueous solution: kinetic and RSM modeling approach. Chem. Eng. Res. Des. S0263876218303198- (2018).

34. Konicki, W., Hełminiak, A., Arabczyk, W. \& Mijowska, E. Removal of anionic dyes using magnetic Fe@graphite core-shell nanocomposite as an adsorbent from aqueous solutions. J. Colloid Interf. Sci. 497, 155-164 (2017).

35. Konicki, W., Cendrowski, K., Chen, X. \& Mijowska, E. Application of hollow mesoporous carbon nanospheres as an high effective adsorbent for the fast removal of acid dyes from aqueous solutions. Chem. Eng. J. 228, 824-833 (2013).

36. Guedidi et al. The effects of the surface oxidation of activated carbon, the solution $\mathrm{pH}$ and the temperature on adsorption of ibuprofen. Carbon 54, 432-443 (2013).

37. Wang, X. et al. Nitrogen-enriched ordered mesoporous carbons through direct pyrolysis in ammonia with enhanced capacitive performance. J. Mater.s Chem. A 1, 7920-7926 (2013).

38. Sánchez-Sánchez, Á., Suárez-García, F., Martínez-Alonso, A. \& Tascón, J. Synthesis, characterization and dye removal capacities of N-doped mesoporous carbons. J Colloid Interface Sci 450, 91-100 (2015).

39. Hou, S. C. et al. Nitrogen-doped graphene for dye-sensitized solar cells and the role of nitrogen states in triiodide reduction. Energy Environ. Sci. 6, 3356-3362, https://doi.org/10.1039/c3ee42516a (2013).

40. Gong, J., Lin, H. J., Antonietti, M. \& Yuan, J. Y. Nitrogen-doped porous carbon nanosheets derived from poly(ionic liquid)s: hierarchical pore structures for efficient CO2 capture and dye removal. J. Mater. Chem. A 4, 7313-7321, https://doi.org/10.1039/ c6ta01945e (2016).

41. Zhao, Y. Q. et al. Hierarchically porous and heteroatom doped carbon derived from tobacco rods for supercapacitors. J. Power Sources 307, 391-400, https://doi.org/10.1016/j.jpowsour.2016.01.020 (2016).

42. Liu, Z., Zhang, F., Liu, T., Peng, N. \& Gai, C. Removal of azo dye by a highly graphitized and heteroatom doped carbon derived from fish waste: Adsorption equilibrium and kinetics. J. Environ. Manage. 182, 446-454 (2016).

43. Masakazu, I., Yasuhiro, T., Naoki, S. \& Seitaro, N. Remarkable effect of pore size on the catalytic activity of mesoporous silica for the acetalization of cyclohexanone with methanol. J. Am. Chem. Soc. 125, 13032-13033 (2003).

44. Moussavi, G. \& Khosravi, R. The removal of cationic dyes from aqueous solutions by adsorption onto pistachio hull waste. Chem. Eng. Res. Des. 89, 2182-2189, https://doi.org/10.1016/j.cherd.2010.11.024 (2011).

45. Njoku, V. O., Foo, K. Y., Asif, M. \& Hameed, B. H. Preparation of activated carbons from rambutan (Nephelium lappaceum) peel by microwave-induced KOH activation for acid yellow 17 dye adsorption. Chem. Eng. J. 250, 198-204 (2014).

46. Alves, M. D., Aracri, F. M., Cren, É. C. \& Mendes, A. A. Isotherm, kinetic, mechanism and thermodynamic studies of adsorption of a microbial lipase on a mesoporous and hydrophobic resin. Chem. Eng. J. 311, S138589471631631X (2016).

47. Wu, Z., Zhang, X., Zhou, C., Pang, J. L. \& Zhang, P. AdsorptionNeutralization Model and Floc Growth Kinetics Properties of AluminumCoagulants Based on Sips and Boltzmann Equations. ACS Appl. Mater. Interfaces 9, 5992 (2017).

\section{Acknowledgements}

This work is supported by National Nature Science Foundation of China (No. 51778383) and Sichuan Science and Technology Program (2019YFS0500). 


\section{Author contributions}

Q.Y.Z., W.H.C. and X.J. wrote the main manuscript text and prepared all figures and tables; W.H.C. and S.G.M. designed and carried out the experiments; W.H.C., S.G.M. and B.D.W. discussed the related results; X.J. and H.Y. L. obtained funding; Q.Y.Z., W.H.C. and B.D.W. designed the research and discussed the results. All authors reviewed the manuscript.

\section{Competing interests}

The authors declare no competing interests.

\section{Additional information}

Supplementary information is available for this paper at https://doi.org/10.1038/s41598-020-57823-z.

Correspondence and requests for materials should be addressed to X.J.

Reprints and permissions information is available at www.nature.com/reprints.

Publisher's note Springer Nature remains neutral with regard to jurisdictional claims in published maps and institutional affiliations.

(c) (i) Open Access This article is licensed under a Creative Commons Attribution 4.0 International License, which permits use, sharing, adaptation, distribution and reproduction in any medium or format, as long as you give appropriate credit to the original author(s) and the source, provide a link to the Creative Commons license, and indicate if changes were made. The images or other third party material in this article are included in the article's Creative Commons license, unless indicated otherwise in a credit line to the material. If material is not included in the article's Creative Commons license and your intended use is not permitted by statutory regulation or exceeds the permitted use, you will need to obtain permission directly from the copyright holder. To view a copy of this license, visit http://creativecommons.org/licenses/by/4.0/.

(c) The Author(s) 2020 